\title{
Presymptomatic Alterations in Amino Acid Metabolism and DNA Methylation in the Cerebellum of a Murine Model of Niemann-Pick Type C Disease
}

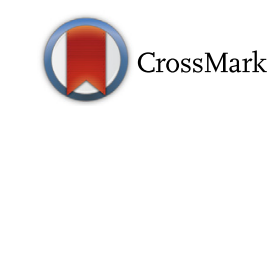

\author{
Barry E. Kennedy, ${ }^{*}$ Amos S. Hundert, ${ }^{\dagger}$ Donna Goguen, ${ }^{\dagger}$ Ian C.G. Weaver ${ }^{\dagger}{ }^{\circ}$ and Barbara Karten*
}

From the Departments of Biochemistry and Molecular Biology* and Psychology and Neuroscience, ${ }^{\dagger}$ Dalhousie University, Halifax, Nova Scotia, Canada

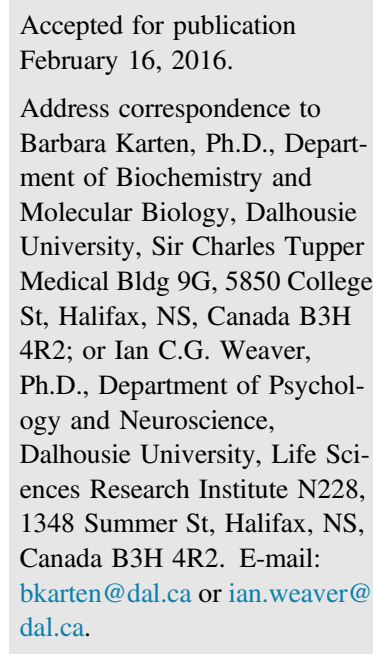

Address correspondence to Barbara Karten, Ph.D., Department of Biochemistry and Molecular Biology, Dalhousie University, Sir Charles Tupper Medical Bldg 9G, 5850 College St, Halifax, NS, Canada B3H 4R2; or Ian C.G. Weaver, Ph.D., Department of Psychology and Neuroscience,

Dalhousie University, Life Sciences Research Institute N228, 1348 Summer St, Halifax, NS, Canada B3H 4R2. E-mail: bkarten@dal.ca orian.weaver@ dal.ca.

\begin{abstract}
The fatal neurodegenerative disorder Niemann-Pick type $C$ (NPC) is caused in most cases by mutations in NPC1, which encodes the late endosomal NPC1 protein. Loss of NPC1 disrupts cholesterol trafficking from late endosomes to the endoplasmic reticulum and plasma membrane, causing cholesterol accumulation in late endosomes/lysosomes. Neurons are particularly vulnerable to this cholesterol trafficking defect, but the pathogenic mechanisms through which NPC1 deficiency causes neuronal dysfunction remain largely unknown. Herein, we have investigated amino acid metabolism in cerebella of NPC1-deficient mice at different stages of NPC disease. Imbalances in amino acid metabolism were evident from increased branched chain amino acid and asparagine levels and altered expression of key enzymes of glutamine/glutamate metabolism in presymptomatic and early symptomatic NPC1-deficient cerebellum. Increased levels of several amino acid intermediates of one-carbon metabolism indicated disturbances in folate and methylation pathways. Alterations in DNA methylation were apparent in decreased expression of DNA methyltransferase $3 a$ and methyl-5'-cytosine-phosphodiester-guaninedomain binding proteins, reduced 5-methylcytosine immunoreactivity in the molecular and Purkinje cell layers, demethylation of genome-wide repetitive LINE-1 elements, and hypermethylation in specific promoter regions of single-copy genes in NPC1-deficient cerebellum at early stages of the disease. Alterations in amino acid metabolism and epigenetic changes in the cerebellum at presymptomatic stages of NPC disease represent previously unrecognized mechanisms of NPC pathogenesis. (Am J Pathol 2016, 186: 1582-1597; http://dx.doi.org/10.1016/j.ajpath.2016.02.012)
\end{abstract}

In mammalian cells, a dynamic network of cholesterol trafficking pathways maintains cholesterol content of each subcellular membrane. The late endosomal transmembrane protein Niemann-Pick type C1 (NPC1) and the NPC2 protein in the lysosome lumen functionally interact to transport cholesterol from endosomes to the plasma membrane and the endoplasmic reticulum. ${ }^{1,2}$ Loss of function of either of these proteins leads to late endosomal accumulation of unesterified cholesterol and imbalances in cellular cholesterol homeostasis, and causes the fatal neurodegenerative NPC disease.

Of cases, $95 \%$ are because of mutations in NPC1. NPC1deficient cells also display a range of abnormalities in endosomal trafficking, sphingolipid and ganglioside metabolism, calcium homeostasis, and mitochondrial function. ${ }^{3,4}$ NPC disease is characterized by progressive loss of Purkinje cells (PCs) in the cerebellum and a wide range of morphological and functional abnormalities in other brain areas and peripheral tissues. Symptoms include loss of motor coordination and control of muscle tone, impaired eye movement and swallowing reflex, seizures, and cognitive decline. ${ }^{5}$ The age of onset of NPC disease varies widely without a clear genotype-phenotype relationship, suggesting that additional genetic, epigenetic, or environmental factors influence NPC disease pathology. Therapeutic approaches for NPC disease are limited and largely symptomatic, with

\footnotetext{
Supported by Natural Sciences and Engineering Research Council of Canada Discovery grants 401978-2011 (B.K.) and 436204-2013 (I.C.G.W.) and Nova Scotia Health Research Foundation (NSHRF) operating grant MED-PROJECT-2010-6804 (B.K.). B.E.K. received a postgraduate fellowship from the NSHRF (MED-SS-2012-8683).

Disclosures: None declared.
} 
the possible exception of cyclodextrins and histone deacetylase inhibitors, which are being explored as possible treatment strategies to mobilize endosomal cholesterol. ${ }^{6-10}$ However, secondary pathogenic effects may not be fully reversible by cholesterol mobilization, and a deeper understanding of mechanisms through which NPC1 deficiency and defective cholesterol trafficking lead to neurological abnormalities is needed to develop treatment options. Recent findings of increased oxidative stress in cell and animal models of NPC disease and in NPC patients have increased interest in the role of oxidative stress and mitochondrial function in NPC disease pathogenesis. ${ }^{11-15}$ Metabolomics, gene expression, and proteomics analyses show alterations in brain energy metabolism in several areas of NPC1-deficient murine brains, and indications for impaired pyruvate oxidation in cerebella of presymptomatic NPC1-deficient mice. ${ }^{12,16}$ Defects in pyruvate oxidation limit the efficient use of glucose for mitochondrial energy metabolism, and often lead to an up-regulation of compensatory pathways, including glycolysis to lactate and oxidation of amino acids, such as glutamine.

In addition, several amino acids are key intermediates of one-carbon metabolism and thus influence folate-dependent pathways and methylation reactions. Serine and other amino acids are donors for folate-activated methyl groups, which are required for many biosynthetic processes and the synthesis of methionine from homocysteine. Methionine is the precursor for S-adenosylmethionine (S-AdoMet), which, in turn, provides methyl groups for DNA methylation, a crucial epigenetic modification of the genome that regulates processes, including transcription, chromatin structure, $\mathrm{X}$ chromosome inactivation, genomic imprinting, and chromosome stability. ${ }^{17,18}$ DNA methyltransferases (DNMT1, DNMT3A, and DNMT3B) catalyze the transfer of a methyl group from S-AdoMet to cytosine in 5'-cytosine-phosphodiester-guanine (CpG)-3' dinucleotides, producing 5-methylcytosine (5-mC) in a cell-specific pattern. ${ }^{19,20}$ Although DNMT1 maintains the methylome in dividing cells by copying the methylation pattern during DNA replication, DNMT3A and DNMT3B are developmentally regulated enzymes required for de novo DNA methylation. ${ }^{19,21}$ DNA methylation of gene promoter regions or enhancer sites often correlates with transcriptional silencing through methylation-sensitive transcription factors or methyl-CpG domain binding proteins. ${ }^{22-24}$ This epigenetic gene silencing is modifiable by methyl-donor availability and one-carbon nutrients and is associated with a growing number of human diseases. ${ }^{25}$

Herein, we have analyzed gene expression of key enzymes of glutamate/glutamine and one-carbon metabolism, as well as the free amino acid levels in cerebella and hippocampi from 3- and 5-week-old wild-type (WT) and $\mathrm{NpCl}^{-1-}$ mice to reflect presymptomatic and early symptomatic disease stages. Our findings show alterations of amino acid metabolism consistent with an increase in glutamine oxidation, alterations in one-carbon metabolism, hypomethylation of genome-wide repetitive sequences, and hypermethylation of several single-copy gene promoters in $\mathrm{NpCl}^{-1-}$ cerebellum even before the onset of overt symptoms. Minor alterations were found in the less affected hippocampal region of $\mathrm{Npcl}^{-1-}$ mice. These alterations in amino acid metabolism and DNA methylation could represent additional pathogenic mechanisms in NPC1-deficient brain.

\section{Materials and Methods}

\section{Animals}

NPC1-deficient mice were derived from an in-house breeding colony of BALB/cNctr-Npc1 ${ }^{\mathrm{m} 1 \mathrm{~N}} / \mathrm{J}$ mice heterozygous for a null mutation in $\mathrm{Npcl}$ (originally obtained from The Jackson Laboratory, Bar Harbor, ME, strain 003092). Only WT mice and mice homozygous for the mutation in $\mathrm{Npcl}\left(\mathrm{Npcl}^{-1-}\right)$ were used in this study. All animals were genotyped by PCR using previously described primers. ${ }^{26}$ Mice were fed a normal chow diet (Prolab RMH 3000 5P00*; LabDiet, St. Louis, MO) ad libitum and not fasted before being deeply anesthetized with halothane (Sigma, St. Louis, MO) and terminated by decapitation. Cerebella and hippocampi were removed rapidly and immediately snap frozen in liquid nitrogen. All procedures were approved by the animal ethics committee of Dalhousie University (Halifax, NS, Canada; protocol numbers 10-102 and 10-030) on the basis of the standards established by the Canadian Council of Animal Care.

\section{Amino Acid Analysis}

Aqueous extracts were prepared from brain tissue by homogenization via ultrasonication in a FastPrep-24 instrument (MP Biomedicals Inc., Solon, $\mathrm{OH}$ ) at a final tissue/ methanol/water ratio of $3.2: 1(\mathrm{v} / \mathrm{v})$, followed by extraction with chloroform and water in a final chloroform/methanol/ water ratio of 1:1:0.81. ${ }^{12,27}$ Amino acids were analyzed in the Advanced Protein Technology Center of the SickKids Hospital (Toronto, ON, Canada). Briefly, aqueous extracts were treated with trichloroacetic acid to remove residual proteins, and free amino acids were analyzed by reverse-phase high-performance liquid chromatography with UV detection of the absorption at $254 \mathrm{~nm}$ after precolumn derivatization with phenylisothiocyanate at room temperature.

\section{Gene Expression Analysis by qPCR}

Total RNA was prepared from snap-frozen brain tissue using a commercially available kit (Aurum Total RNA kit; BioRad, Mississauga, ON, Canada). cDNA was prepared from $1 \mu \mathrm{g}$ total RNA using iScript Reverse Transcriptase (BioRad), according to the manufacturer's instruction. Real-time quantitative PCR (qPCR) was performed using the iSYBR Green Mastermix (BioRad) and primers as listed in Table 1. Specificity of the amplification reaction was tested by melt curve analysis, agarose gel electrophoresis, and sequencing of the amplicon. Data were calculated by the Pfaffl method with 
Table 1 Primers Used for Real-Time Quantitative PCR Analysis

\begin{tabular}{|c|c|c|c|}
\hline Target & Gene & Forward primer & Reverse primer \\
\hline Actin & Actb & 5'-AGCCTTCCTTCTTGGGTATGG-3' & $5^{\prime}-$ ACACAGAGTACTTGCGCTCAG- $3^{\prime}$ \\
\hline Alanine aminotransferase 1 & Gpt1 & $5^{\prime}$-AGGCCGTAATCCGCTTTGC-3' & 5'-TCGCCCATGTAGCCCTTAG-3' \\
\hline Alanine aminotransferase 2 & Gpt2 & 5'-TATGCGTTCCCTCGGATTC-3' & 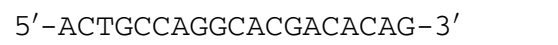 \\
\hline Aspartate aminotransferase 1 & Got1 & $5^{\prime}-\mathrm{ACTCAGGCAAGACTAGAAG-3^{ \prime }}$ & $5^{\prime}$-ATGTTGATCCGACCACTC-3' \\
\hline Aspartate aminotransferase 2 & Got2 & $5^{\prime}-$ GCAGGTAGAGCGGCTGAC- $3^{\prime}$ & $5^{\prime}-$ ATGGCATGGGCAAGGTAG- $3^{\prime}$ \\
\hline D-amino oxidase & Dao & $5^{\prime}-$ TTAAACAGCGTCCGTGACC-3' & 5'-GATTGTGAGCCCGTAACCTC-3' \\
\hline Branched-chain aminotransferase 1 & Bcat1 & $5^{\prime}$-ACGTGAAGCCCTGCTAGTGTTAAG- $3^{\prime}$ & $5^{\prime}$-GGCAACAGAAAGGTGGACATAATC-3 \\
\hline Branched-chain aminotransferase 2 & Bcat2 & $5^{\prime}$-GGCAAGCAACTCCACATACCT-3' & 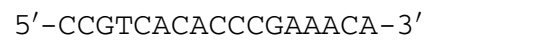 \\
\hline Catechol-0-methyl transferase & Comt & $5^{\prime}$-СССTGACTTCCTGGCGTATG-3' & $5^{\prime}$-GCCTTCTCCAAGCCGTCCAC-3' \\
\hline Cyclophilin & Ppia & 5'-TCTTCTTGCTGGTCTTGCCATTCC-3' & $5^{\prime}-\mathrm{TCCAAAGACAGCAGAAAACTTTCG-3'}$ \\
\hline Cystathionine synthase & Cbs & $5^{\prime}-$ AGTGGCATGGCGACTGA- $3^{\prime}$ & $5^{\prime}-\mathrm{TATCCAGCTTCCCGTCACAC-3^{ \prime }}$ \\
\hline Dihydrofolate reductase & Dhfr & $5^{\prime}-$ AAACTTGACGGCAATCCTAGC- $3^{\prime}$ & $5^{\prime}-$ GCGGAGGCCAGGGTAGGTC-3' \\
\hline DNA methyltransferase 1 & Dnmt1 & 5'-ATCATTTGAGGCGGAAATC- $3^{\prime}$ & 5'-CGTCTCTGTCCTCGGGAGTC-3' \\
\hline DNA methyltransferase $3 a$ & Dnmt3a & $5^{\prime}-\mathrm{AAGACTGGCCTTCTCGACTC-3^{ \prime }}$ & $5^{\prime}-$ GCAATGTAGCGGTCCAC- $3^{\prime}$ \\
\hline DNA methyltransferase $3 b$ & Dnmt3b & $5^{\prime}-\mathrm{AGGGCGACAACCGTCC}-3^{\prime}$ & 5'-CCTGTTCATTCCGGGTAGGT-3' \\
\hline Glial fibrillary acidic protein & Gfap & $5^{\prime}-$ TGCTGGAGGGCGAAGAAA-3' & 5'-CGGATCTGGAGGTTGGAGAA- $3^{\prime}$ \\
\hline Glutamate dehydrogenase & Glud1 & $5^{\prime}-\mathrm{CGCCAGCGAGAAGC-3^{ \prime }}$ & $5^{\prime}$-AAGTAGAGATCGGGAATAACC-3' \\
\hline Glutamine synthetase & Glu1 & $5^{\prime}-\mathrm{TCTCCGCCTCGCTCTCCTGAC-3^{ \prime }}$ & $5^{\prime}-$ TACGGGTCTTGCAGCGCAGTC- $3^{\prime}$ \\
\hline Glycine decarboxylase & Gldc & $5^{\prime}-\mathrm{AGCCACAGAAATCGCCATTC-3^{ \prime }}$ & 5'-GGGCGTGAAATCCATAATCC-3' \\
\hline Insulin growth factor 2 & Igf2 & $5^{\prime}$-GATACATGCTGCCCAAGTAACC-3' & $5^{\prime}$-GACTGACAAAGATGGCCCATAG-3' \\
\hline Methionine adenosyl transferase $2 \mathrm{~A}$ & Mat2a & 5'-TTCATCTTGACCGGAATGAGG-3' & $5^{\prime}-$ CGTAACCAAGGCAATGTACCA-3' \\
\hline Methionine adenosyl transferase 2B & Mat2b & $5^{\prime}$-TTTCACTGGTCTGGCAATGAG-3' & 5'-GCGCTGTGCTCCTATGAC-3' \\
\hline Methyl-CpG-binding protein 2 & Mecp2 & 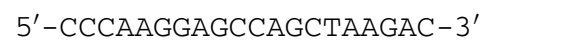 & 5'-GCTTTGCAATCCGCTCTATG-3' \\
\hline Methyl-CpG-domain binding protein 2 & Mbd2 & 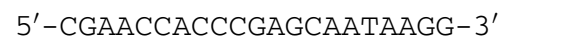 & $5^{\prime}$-GTTACATCTGATGCGCTAAGTCC-3' \\
\hline $\begin{array}{l}\text { Methylenetetrahydrofolate } \\
\text { dehydrogenase } 1\end{array}$ & Mthfd1 & 5'-CATCAAGTGCCGGTATTCTG-3' & 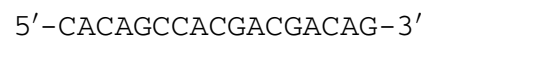 \\
\hline $\begin{array}{l}\text { Methylenetetrahydrofolate } \\
\text { dehydrogenase } 2\end{array}$ & Mthfd2 & 5'-GAAGGTCTGCAATGCCGTTTC-3' & $5^{\prime}$-GACCTGCCAGCCATACCAC-3' \\
\hline Methylene tetrahydrofolate reductase & Mthfr & $5^{\prime}-$ AGCCCAATGCCGTGACGTG- $3^{\prime}$ & $5^{\prime}-$ ATGCGGGATGGCGACTC $-3^{\prime}$ \\
\hline Methionine synthase & Mtr & $5^{\prime}$-TATAAAGTCAGCCCGTGTC-3' & 5'-АACTATGTTCTTGCCGATGTC-3' \\
\hline NRF2 & Nfe2l2 & 5'-TTGGCAGGAGCTATTTTCC-3' & $5^{\prime}-$ GAACAGCGGTAGTATCAGC-3' \\
\hline Phosphog & Pgdh & 5'-GCAGTCATTGTCGGCCTTC-3' & 5'-TGGGAGGTGGTGACATTGAG-3' \\
\hline Phosphate-activated glutaminase 1 & Gls1 & $5^{\prime}$-GACAAGATGGGCAACAGTG-3' & $5^{\prime}-$ CAGTGTATGCGGCAAAC $-3^{\prime}$ \\
\hline Phosphate-activated glutaminase 2 & Gls2 & $5^{\prime}$-GAAGGGCACATTGAGTTGTC-3' & 5'-GTGGTTGAACTGCACAGCATC-3' \\
\hline Phosphoserine aminotransferase & Psat & $5^{\prime}-$ ACTACAGAGGACTCGGCATC- $3^{\prime}$ & 5'-CAGCTTTCAGGCCAATCAG-3' \\
\hline Phosphoserine phosphatase & Psph & $5^{\prime}-\mathrm{AGATGCAGCCGACAGC-3^{ \prime }}$ & 5'-ACTTGGCGTTGTCCTTAAC-3' \\
\hline Serine dehydratase & $S d h$ & $5^{\prime}-$ GTACAGCCGCGTGGTG-3' & 5'-GCTGCGCCAGGCTTATG-3' \\
\hline Serine hydroxymethyltransferase 1 & Shmt1 & 5'-GCCTGTTCTATCGCCTGC-3' & $5^{\prime}-$ AAGTCCTCGGGATGTCAATG-3' \\
\hline Serine hydroxymethyltransferase 2 & Shmt2 & $5^{\prime}$-CATCATAGCTGGCACGAGTG-3' & $5^{\prime}-\mathrm{CAACATCCGCGTACTTGAAAG-3^{ \prime }}$ \\
\hline Thymidylate synthase & Tyms & 5'-AACATTGCCAGCTATGCTC-3' & 5'-GGTCTTGGTTCTCGCTGTAG-3' \\
\hline
\end{tabular}

cyclophilin as a housekeeping gene and standardized to the WT samples of the same age and the same run of the qPCR analysis. ${ }^{28}$ All qPCR data were derived from 8 to 11 mice of each genotype and each age, with the exception of qPCR analyses of hippocampi at 3 weeks of age, which were performed with five animals of each genotype. For clarity, abbreviations throughout the text adhere to the nomenclature for proteins and gene products. Gene names are included in the table listing the primer sequences.

\section{DNA Methylation Analysis by ChIP}

Chromatin immunoprecipitation (ChIP) assays ${ }^{29}$ were performed using a ChIP assay kit (catalog number 06-599; EMD Millipore, Etobicoke, ON, Canada). Briefly, chromatin was immunoprecipitated from WT or $\mathrm{Npcl}^{-1-}$ murine cerebellar and hippocampal homogenates using mouse monoclonal anti-5-mC antibodies (catalog number BI-MECY-0500; AnaSpec Inc., San Jose, CA), normal mouse IgG (catalog number sc-3877; Santa Cruz Biotechnology, Dallas, TX), rabbit polyclonal anti-5hydroxymethylcytosine (5-hmC) antibodies (catalog number 39769; Active Motif, Carlsbad, CA), or normal rabbit IgG (catalog number sc-2027; Santa Cruz Biotechnology). The mouse LINE-1 type-Gf 5' untranslated region (position: chromosome $12: 53558872-53564943$ ) is a 372-bp CpG island located between 49 and 420 nucleotides, showing $>60 \% \mathrm{CpG}$ content and an observed-over-expected $\mathrm{CpG}$ frequency of $>0.6$. Methylation of LINE-1 elements was measured as a marker for global DNA methylation. In 
addition, three well-characterized differentially methylated regions (DMRs) were analyzed, namely the H19 imprinting control region (ICR) of the Igf2/H19 imprinted locus (position: chromosome 7: 142653816-142655810), the Peg3 DMR (position: chromosome 7: 6293901-7043900), and the Dlkl/Gtl2 imprinted domain (position: chromosome 12: 106965233-106983177). All genomic regions were analyzed by qPCR using the SsoFast EvaGreen Supermix (Bio-Rad) and primers LINE1-F (5'-TAAGCCACAGCAGCAGCGG-3') and LINE1-R (5'-CCCAGGTGGTACAGACTCTC-3'); $H 19$ ICR-F (5'-GGAACCGCCAACAAGAAAGT-3') and H19 ICR-R (5'-GGTCTTTCCACTCACAACGG-3'); Peg3 DMR-F (5'-ACCCTGACAAGGAGGTGTCCC-3') and $P e g 3$ DMR-R (5'-GTCTAGTGCACCCACACTGAAC-3'); Dlkl/ Gtl2 ICR-F (5'-GTATGTGTATAGAGATATGTTTATATGGTA- $\left.3^{\prime}\right)$ and Dlkl/Gtl2 ICR-R (5'-GTGTTAAGGTATATTATGTTAGTGTTAGGA-3 ${ }^{\prime}$ ). The specificity of the amplification reaction was assessed by melt curve analysis and agarose gel electrophoresis of the PCR products.

\section{Restriction Enzyme-Based DNA Methylation Analysis}

The 5-hmC and 5-mC levels in the mouse LINE-1 type-Gf 5' untranslated region region were measured by a restriction enzyme-based assay (EpiMark kit; catalog number E3317S; New England Biolabs, Ipswich, MA) using the differential susceptibility of methylated and hydroxymethylated DNA to cleavage by HpaII and MspI. Genomic DNA was prepared using the Qiagen DNeasy mini kit and treated with or without T4 phage $\beta$-glucosyltransferase (T4-BGT; catalog number M0357S; New England Biolabs) to glucosylate 5-hmC residues, rendering existing MspI sites non-cleavable. HpaII cleavage is prevented by either 5-hmC or 5-mC. Glucosylated genomic DNA (100 ng) was digested with $10 \mathrm{U}$ of HpaII, MspI, or no enzyme (mock digestion) at $37^{\circ} \mathrm{C}$ overnight, followed by inactivation for 20 minutes at $80^{\circ} \mathrm{C}$. The HpaIIand MspI-resistant fraction was quantified by qPCR using primers designed around three HpaII/MspI sites (LINE1-F, 5'-TAAGCCACAGCAGCAGCGG-3'; and LINE1-R, 5'-CCCAGGTGGTACAGACTCTC- $3^{\prime}$ ), normalizing to the mock digestion control and to two regions lacking HpaII/MspI sites. Resistance to MspI directly translates into percentage of 5 -hmC. The 5 -mC levels were obtained by subtracting the 5-hmC contribution from the total HpaII resistance.

\section{Immunohistochemistry}

Serial sagittal sections ( $20 \mu \mathrm{m}$ thick) of frozen cerebellar tissue were cut on a cryostat, thaw mounted onto positively charged microscope slides, cooled within the cryostat to $-20^{\circ} \mathrm{C}$, and then stored at $-80^{\circ} \mathrm{C}$. Immunohistochemistry was performed essentially as previously described ${ }^{30}$ with the addition of an acid-wash step to reduce background in the 5-mC staining. Briefly, sections were dried for 15 minutes in an incubator set at $37^{\circ} \mathrm{C}$, rinsed in $0.01 \mathrm{~mol} / \mathrm{L}$ phosphate-buffered saline, and fixed in $4 \%$ paraformaldehyde $(\mathrm{pH}$ 7.4). The tissue was immersed in 50\% ethanol for 30 minutes, rinsed, incubated in 2 $\mathrm{mol} / \mathrm{L} \mathrm{HCl}$ for 30 minutes, neutralized with three rinses of 0.1 $\mathrm{mol} / \mathrm{L}$ borate buffer, then permeabilized and blocked in phosphate-buffered saline with 5\% donkey serum and $0.3 \%$ Triton X-100. Permeabilized tissue was incubated in M.O.M. proprietary Mouse Ig Blocking Reagent (M.O.M. Basic Kit, catalog number BMK-2202; Vector Laboratories Inc., Burlingame, CA), followed by incubation with primary antibodies for 24 hours at $4^{\circ} \mathrm{C}$. The primary antibodies used were mouse anti-5-mC (catalog number BI-MECY-0500; AnaSpec, Inc.), rabbit anti-pyruvate dehydrogenase (PDH) E1- $\alpha$ subunit (ab180759; Abcam, Cambridge, MA), rabbit anti-calbindin D28K (catalog number 214-002; Cedarlane, Hornby, ON, Canada), mouse or rabbit anti-NeuN [catalog number ab177487 (Abcam) or catalog number MAB377 (EMD Millipore)], and rabbit anti-glial fibrillary acidic protein (GFAP; catalog number 2033; Dako, Carpinteria, CA). All primary antibody concentrations used were 1:500. Slices were incubated in M.O.M. biotinylated anti-mouse IgG (1:250; supplied in the Vector M.O.M. Basic Kit) for 10 minutes, followed by Cy3-conjugated streptavidin and Cy5-conjugated AffiniPure donkey anti-rabbit IgG (1:400; catalog number 016-160-084 and catalog number 711-175-152; Jackson ImmunoResearch Laboratories, West Grove, PA). In addition, slices were stained with $0.25 \%$ DAPI (Roche Life Science, Indianapolis, IN) for 1 minute. The same staining procedure without primary antibodies served as a negative control (Supplemental Figure S1). Slides were mounted in PermaFluor Aqueous Mounting Medium (Thermo Fisher Scientific, Waltham, MA). Images were acquired with a Nikon TE2000 epifluorescence microscope with an Orca charge-coupled device camera (Hamamatsu, Hamamatsu City, Japan) and $20 \times$ or $40 \times$ objectives or a Zeiss Axio Imager Z2 fluorescent microscope (Carl Zeiss, Oberkochen, Germany) and a high-resolution color digital camera using a $10 \times$ objective. At least four sections were examined per animal, with three to four mice per genotype. Fluorescence intensity was quantified using the open source software ImageJ versions $1.49 \mathrm{v}$ and $1.50 \mathrm{i}(\mathrm{NIH}$, Bethesda, MD; http://rsbweb. nih.gov/ij), and images were taken with the $20 \times$ objective. Images were background subtracted using a rolling ball algorithm with a 400-pixel diameter. For analysis of PDH staining, PCs were outlined using the free-hand tool, and the mean fluorescence intensity was analyzed separately for each cell. In the granular layer (GL), where cells could not be outlined separately, PDH staining was quantified as the average fluorescence intensity of six randomly chosen regions of interest (ROIs) in the molecular layer (ML) or GL. For 5-mC, the fluorescence intensity was determined in individual PC nuclei, and in the ML, GL, and PC layer (PCL). PC nuclei were identified on the basis of their colocalization with calbindin. Because the calbindin stain shows the whole PC cell body, the ROI was defined to outline the nucleus on the basis of its 5-mC fluorescence. Only nuclei that were in sharp focus and separate from surrounding non-PC nuclei were included in the analysis. In the ML, out-of-focus nuclei were erased, and remaining nuclei were defined as separate 

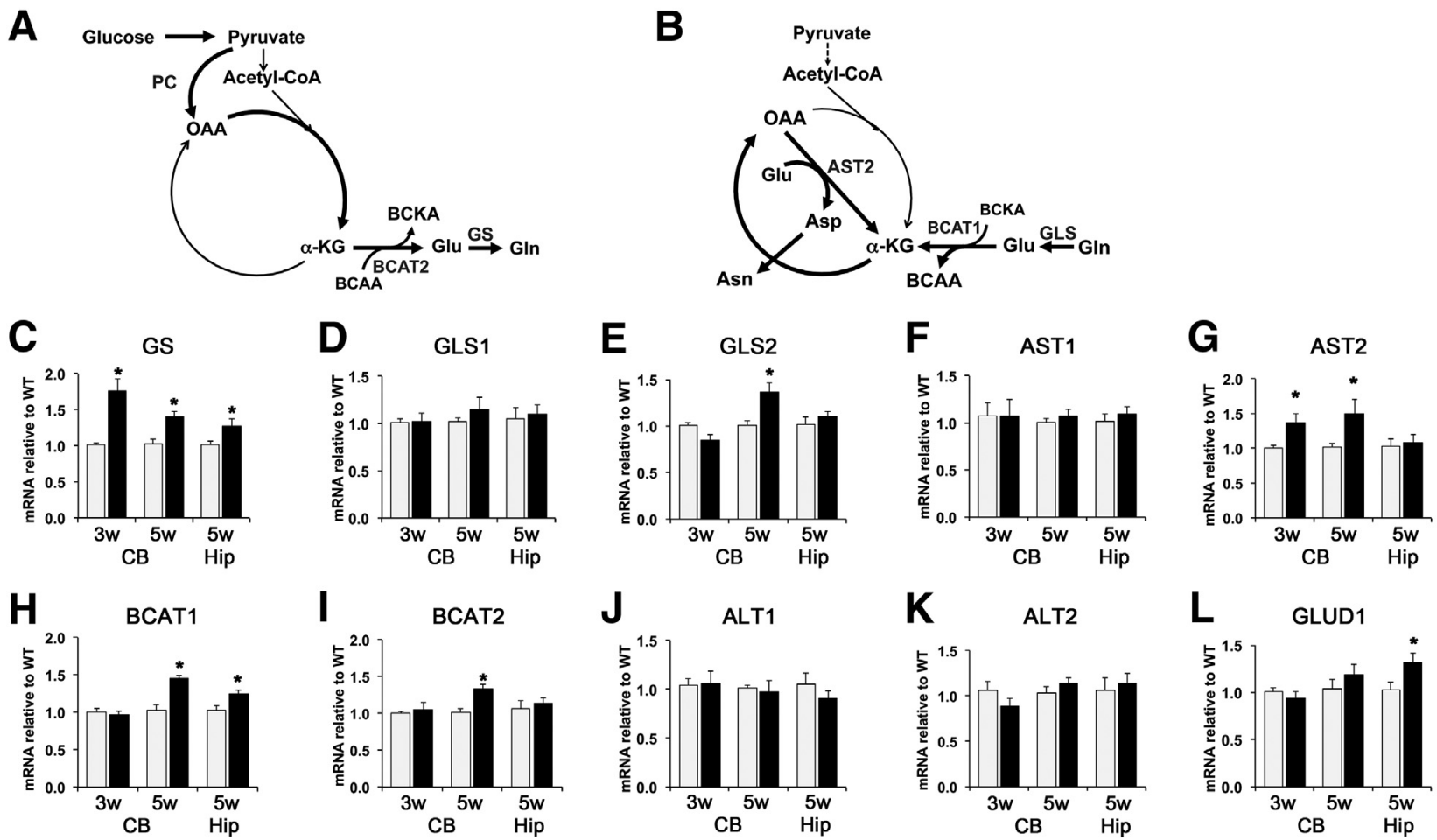

Figure 1 Expression of key enzymes of glutamine/glutamate metabolism in $\mathrm{Npc1}^{-/-}$cerebellum and hippocampus. A: De novo synthesis of glutamine in astrocytes: the conversion of pyruvate to oxaloacetate $(0 \mathrm{AA})$ by pyruvate carboxylase provides citric acid cycle intermediates for the amination or transamination of $\alpha$-ketoglutarate $(\alpha-K G)$ to glutamate $(G l u)$, which is then converted to glutamine (Gln) by glutamine synthetase (GS). Branched chain amino acid aminotransferase 2 (BCAT2) is a key aminotransferase in astrocytes and converts branched chain amino acids (BCAAs) to branched chain ketoacids (BCKAs). B: Overview of glutamine oxidation in a truncated Krebs' cycle: glutamine is deamidated by glutaminases to glutamate, which is deaminated or transaminated to $\alpha$-KG. Shown is the transamination by BCAT1. Mitochondrial aspartate aminotransferase AST2 converts OAA and Glu to aspartate (Asp) and $\alpha$-KG. Asp can be converted to asparagine (Asn) by asparagine synthase. The truncated Krebs' cycle produces NADH and FADH ${ }_{2}$ without acetyl-CoA oxidation. C-L: RNA extracts were prepared from snap-frozen cerebella (CB) and hippocampi (Hip) of 3- or 5-week-old wild-type (WT, white bars) and $\mathrm{NpC1}^{-1-}$ (black bars) mice and mRNA levels of the indicated target genes were analyzed by real-time quantitative PCR using cyclophilin as housekeeping gene. Data are expressed as means \pm SEM $(\mathbf{C}-\mathbf{L})$. ${ }^{*} P<0.05$.

ROIs by thresholding. The fluorescence intensities of these ML nuclei were averaged to yield one data point for each image. For the GL, the mean fluorescence intensity of six ROIs across cell clusters was averaged to yield one data point for each image. For the PCL, the mean fluorescence intensity of five narrow ROIs along the border of GL and ML was averaged to yield one data point for each image. The PCL ROI contained both PC and non-PC nuclei, which are likely mostly Bergmann glia. Images were blinded (B.K.) to minimize bias, and at least 10 images with three to eight PCs each were analyzed per mouse.

\section{Statistical Analysis}

All sample sets were subjected to a Shapiro-Wilk test to verify that the data followed a normal distribution, then a two-tailed $t$ test was used for the comparison of data from $\mathrm{Npcl}^{-1-}$ and age-matched WT control. Statistical significance was assumed for $P<0.05$. DNA methylation results were subjected to analysis of variance for repeated measures with Tukey's honestly significant difference post hoc tests. The Statistical Package for the Social Sciences software version 22 (SPSS Inc., Chicago, IL) was used for data analysis.

\section{Results}

\section{Adaptations of Glutamate Metabolism in $\mathrm{Npc1}^{-/-}$ Cerebellum and Hippocampus}

Previous studies have shown alterations in energy metabolism in NPC1-deficient murine brain that suggest impaired pyruvate oxidation in $\mathrm{Npcl}^{-1-}$ cerebellum. ${ }^{12,16}$ Amino acids, and in particular glutamine/glutamate, can serve as additional energy substrates when glucose metabolism is deficient. In the brain, astrocytes synthesize glutamine from glutamate or de novo from glucose (Figure 1A), whereas neurons absorb glutamine and convert it to glutamate to replenish the neurotransmitter pool. Oxidation of glutamate as an energy substrate can occur through its conversion to $\alpha$-ketoglutarate, Krebs' cycle activity, and malic enzyme activity forming pyruvate or through the activity of a truncated Krebs' cycle involving mitochondrial aspartate aminotransferase 2 (Figure 1B). To investigate potential adaptations in glutamine/glutamate metabolism in $\mathrm{Npcl}^{-1-}$ cerebellum, we first analyzed gene expression levels of glutamine synthetase, glutaminases, aminotransferases, and glutamate dehydrogenase in WT and 
A

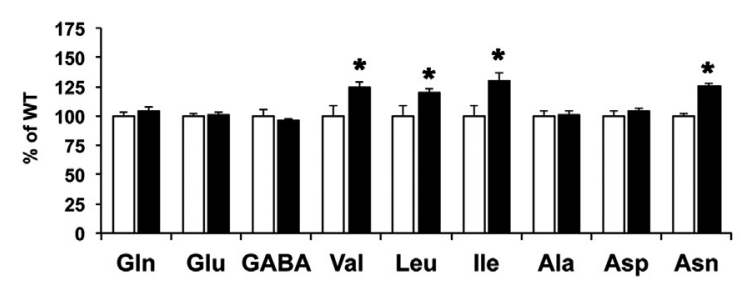

C

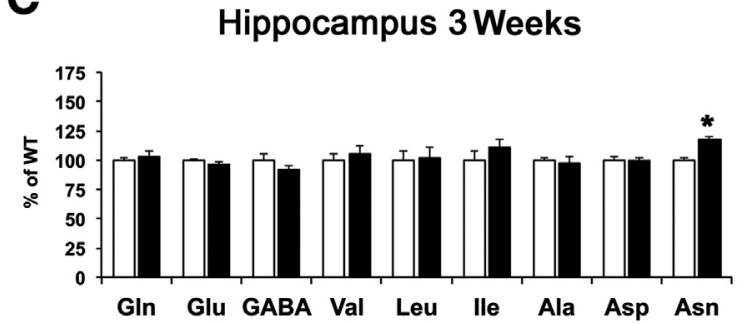

B

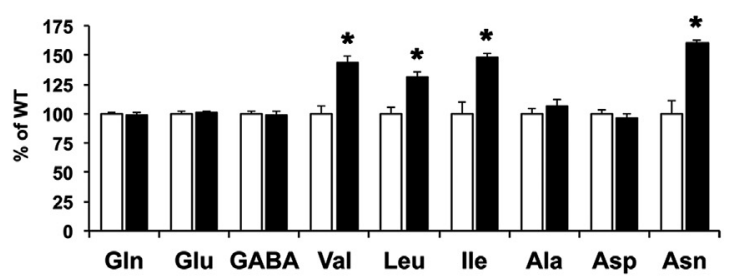

D

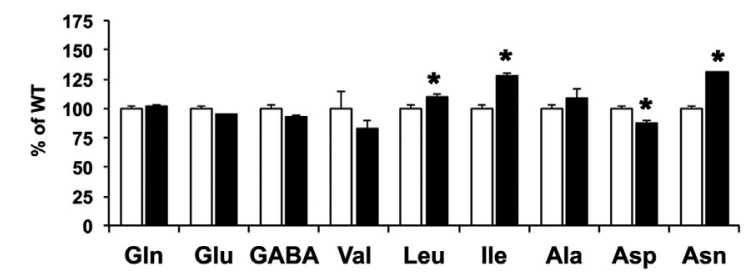

Figure 2 Levels of amino acids related to glutamine/glutamate metabolism in $\mathrm{NpC1}^{-/}$cerebellum and hippocampus. Free amino acids were analyzed by reverse-phase high-performance liquid chromatography in aqueous extracts prepared from snap-frozen cerebella (A and $\mathbf{B}$ ) and hippocampi (C and $\mathbf{D})$ of $3-$ or 5-week-old wild-type (WT, white bars) and $\mathrm{NpC1}^{-/-}$(black bars) mice, as indicated. Amino acid levels are shown as mole percentage of each amino acid per total free amino acids expressed per the average of all WT samples of the same age. Data are expressed as means \pm SEM (A-D). $n=6$ to 8 mice of each genotype for each age (A-D). ${ }^{*} P<0.05$.

$\mathrm{Npcl}^{-1-}$ cerebellum at 3 and 5 weeks of age, to reflect presymptomatic and early symptomatic stages of NPC disease, ${ }^{31}$ and in hippocampi of 5-week-old mice for a comparison with a less affected brain region. Astrocytic glutamine synthetase was significantly increased in $\mathrm{Npcl}^{-1-}$ cerebellum at 3 and 5 weeks of age (Figure 1C). Glutaminase expression was unchanged in $\mathrm{Npcl}^{-/-}$cerebellum at 3 weeks of age, but glutaminase 2 mRNA was increased at 5 weeks of age (Figure 1, D and E). Mitochondrial aspartate aminotransferase 2 (AST2) and both isoforms of branched chain aminotransferase (BCAT 1 and 2) showed increased mRNA levels in $\mathrm{Npcl}^{-1-}$ cerebellum at 5 weeks of age, whereas cytosolic AST1 and alanine aminotransferases were unchanged (Figure 1, F-K). AST2 mRNA levels were also increased at 3 weeks of age (Figure $1 \mathrm{G}$ ). In $\mathrm{Npcl}^{-1-}$ hippocampus, mRNA levels of glutamine synthetase, BCAT1, and glutamate dehydrogenase were increased at 5 weeks of age (Figure 1, C, H and L), respectively. No changes were observed in mRNA levels of these genes in hippocampi of 3-week-old $\mathrm{NpCl}^{-1-}$ mice (data not shown). Glial activation is a well-known characteristic of NPC1-deficient brain. Our previous study showed 3- and 11-fold increased mRNA levels of GFAP and 1.3- and 1.7-fold increased mRNA levels of the antioxidant response factor nuclear factor (erythroid-derived 2)-like 2 (NRF2) in $\mathrm{Npcl}^{-1-}$ cerebellum at 3 and 5 weeks of age, respectively. ${ }^{12}$ In this study, GFAP and NRF2 mRNA levels were also increased in $\mathrm{Npcl}^{-1-}$ hippocampus at 3 weeks (GFAP mRNA, $3.6 \pm 0.38$-fold; NRF2 mRNA, $1.6 \pm 0.12$-fold; $\mathrm{Npcl}^{-1-}$ versus WT); however, in contrast to $\mathrm{Npcl}^{-1-}$ cerebellum, no further increase was observed in $\mathrm{Npcl}^{-1-}$ hippocampus at 5 weeks of age (GFAP mRNA, $3.5 \pm 0.34$-fold; NRF2 mRNA, $1.6 \pm 0.12$-fold; $\mathrm{Npcl}^{-1-}$ versus WT).
The alterations in gene expression were associated with significant changes in amino acid levels. Although the total levels of glutamine, glutamate, and GABA were not altered, all three branched chain amino acids (BCAAs) were increased in $\mathrm{NpCl}^{-1-}$ cerebellum at 3 and 5 weeks of age (Figure 2, A and B), suggesting a shift of the transamination equilibrium toward the production of BCAA and $\alpha$-ketoglutarate from branched chain ketoacids and glutamate. Transamination in this direction is typical for neurons (Figure 1B), whereas astrocytes mostly use BCAA to produce branched chain ketoacids (Figure 1A). ${ }^{32-34}$ The levels of aspartate and alanine, two other key transamination substrates, were not altered in $\mathrm{Npcl}^{-1-}$ cerebellum either at 3 or 5 weeks of age; however, the levels of asparagine, which is synthesized from aspartate, were significantly increased at both ages (Figure 2, A and B). Significant changes were observed in $\mathrm{NpCl}^{-/-}$hippocampus, but did not seem to develop as early as in $\mathrm{Npcl}^{-1-}$ cerebellum. Thus, BCAA levels were unchanged in $\mathrm{NpCl}^{-/-}$hippocampus at 3 weeks of age, and only leucine and isoleucine, but not valine, were increased at 5 weeks of age (Figure 2, C and D). Although asparagine levels were increased at both ages, aspartate levels decreased in $\mathrm{Npcl}^{-/-}$hippocampus at 5 weeks of age. In a previous study, ${ }^{1} \mathrm{H}-\mathrm{NMR}$ analysis showed decreased GABA levels in $\mathrm{NpCl}^{-1-}$ hippocampus at 3 weeks of age; ${ }^{12}$ in the present study, the trend to lower GABA levels in $\mathrm{Npcl}^{-/-}$hippocampus did not reach significance. Supplemental Table S1 lists the mole percentage values for all profiled amino acids in $\mathrm{Npcl}^{-/-}$cerebellum and hippocampus at 3 and 5 weeks of age.

The observed alterations in mRNA and amino acid levels in $\mathrm{NpCl}^{-1-}$ cerebellum suggested a shift in amino acid metabolism consistent with an increased entry of glutamate into the 

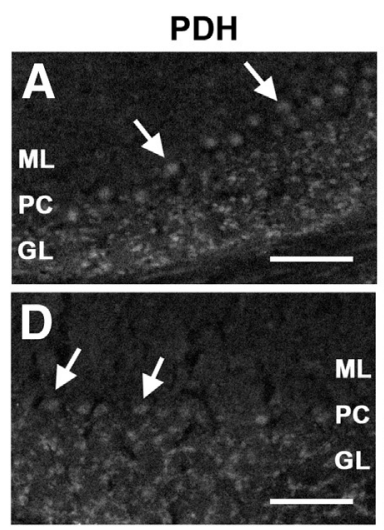

PDH
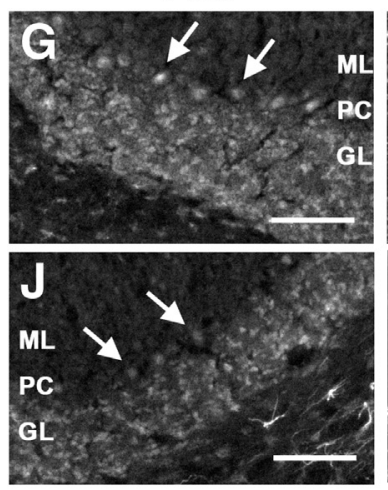

M

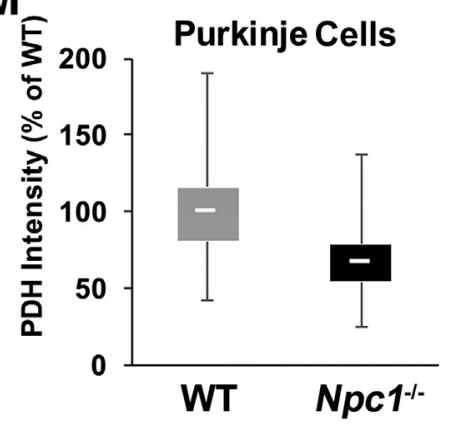

NeuN
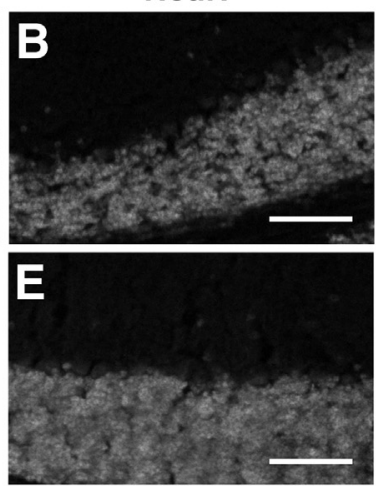

GFAP
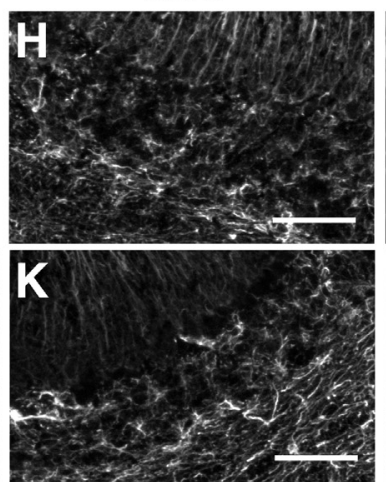

N

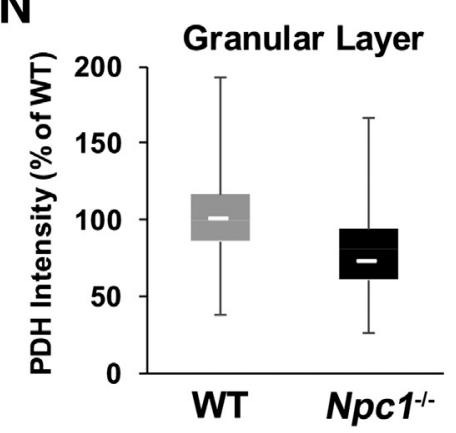

DAPI

DAPI
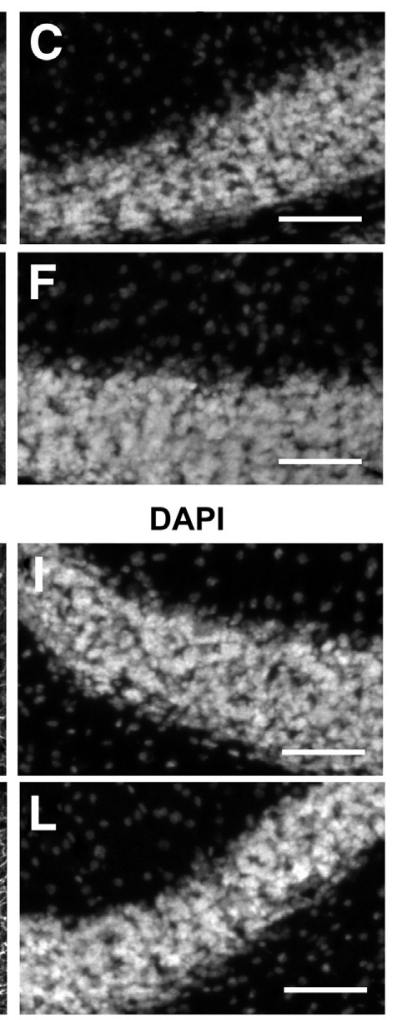

Figure 3 Lower pyruvate dehydrogenase (PDH) levels in Purkinje cells and granular layer. Cerebellar sections from 3-week-old wild-type (WT) and $\mathrm{NpC1}^{-/-}$mice were immunostained with antibodies against PDH, NeuN, and DAPI or against PDH, glial fibrillary acidic protein (GFAP), and DAPI. A-C: WT sections stained with PDH (A), NeuN (B), and DAPI (C). D-F: $\mathrm{NpC1}^{-/-}$ sections stained with PDH (D), NeuN (E), and DAPI (F). G-I: WT sections stained with PDH (G), GFAP (H), and DAPI (I). J-L: Npc1 ${ }^{-/}$sections stained with PDH (J), GFAP (K), and DAPI (L). Images were acquired with a $20 \times$ objective with constant exposure settings. M: Fluorescence intensity in Purkinje cell (PC) bodies (white arrows). $\mathrm{N}$ : Fluorescence intensity in the granular layer (GL). Images derived from costaining with NeuN and with GFAP were analyzed and standardized to the average of PDH intensity in the WT of the respective staining protocol. Box and whisker plots show the means and distribution of PDH fluorescence intensity in PC and GL of eight images for each mouse and each staining protocol. Box boundaries indicate the upper and lower quartile; white lines indicate the mean; error bars indicate the highest and lowest value ( $\mathrm{M}$ and $\mathrm{N}$ ). Scale bars $=40 \mu \mathrm{m}(\mathbf{A}-\mathbf{L})$. ML, molecular layer.
Krebs' cycle as $\alpha$-ketoglutarate, and activity of a truncated cycle that bypasses the citrate synthase step and thus decreases the need for acetyl-CoA from pyruvate oxidation.

To determine whether metabolic alterations occur in PCs, which are most affected by NPC1 deficiency, we performed immunohistochemistry on cerebellar sections of 3-week-old WT and $\mathrm{Npcl}^{-1-}$ mice. We chose PDH as a marker, because a study by Cologna et al $^{16}$ and our own our previous work $^{12}$ had shown decreased protein levels of PDH in presymptomatic $\mathrm{Npcl}^{-/-}$murine cerebellum. Consistent with previous reports about cerebellar PDH distribution, ${ }^{35,36}$ $\mathrm{PDH}$ staining was generally brightest in PCs, with some staining in the GL, where it colocalized with the neuronal marker NeuN, and relatively little fluorescence in the ML (Figure 3, A-F). Astrocytic GFAP and PDH only colocalized in some areas of the white matter (Figure 3, G-L). The fluorescence intensity in PC and in the GL was significantly lower in $\mathrm{Npcl}^{-1-}$ sections than in WT sections (Figure 3, M and N), indicating lower levels of PDH in $\mathrm{Npcl}^{-1-}$ neurons, including PCs.

\section{Alterations in One-Carbon Metabolism in $\mathrm{Npc1}^{-/-}$ Cerebellum}

One-carbon metabolism is critical for generating the precursors of DNA bases and for methylation of lipids and DNA. Several amino acids are key metabolites of one-carbon metabolism and thus influence epigenetic regulation of gene expression. At 3 weeks of age, serine and threonine were already increased, and methionine showed a strong trend to increased levels (Figure 4A). At 5 weeks of age, serine, threonine, methionine, glycine, and cystathionine levels were increased in $\mathrm{Npcl}^{-/-}$cerebellum (Figure 4B). In $\mathrm{Npcl}^{-/-}$ hippocampus, serine and threonine levels were increased at 3 

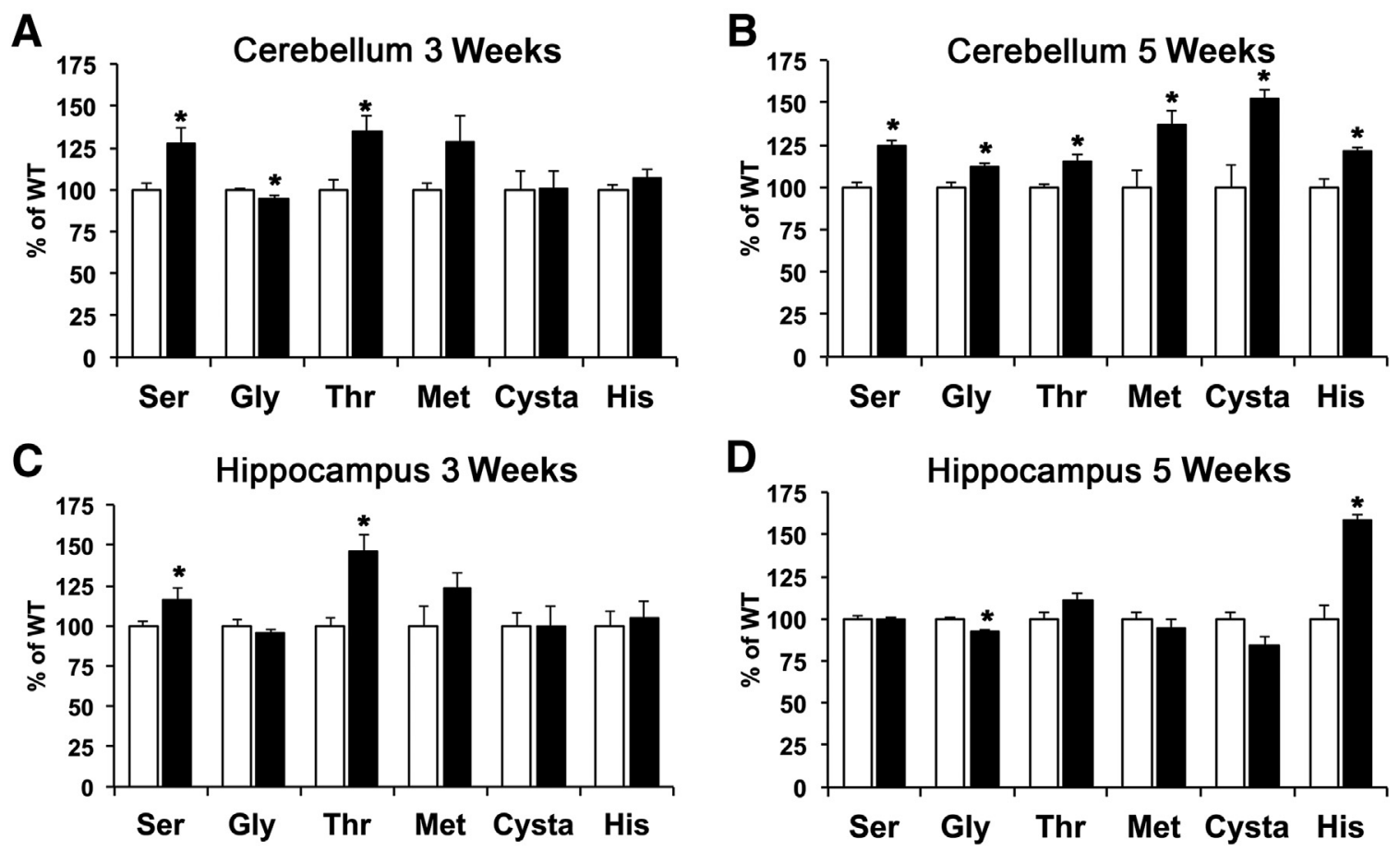

Figure 4 Levels of amino acids related to one-carbon metabolism in $\mathrm{NpC1}^{-/-}$cerebellum and hippocampus. Free amino acids were analyzed by reversephase high-performance liquid chromatography in aqueous extracts prepared from snap-frozen cerebella (A and B) and hippocampi (C and D) of 3- or 5-weekold wild-type (WT, white bars) and NpC1-/- (black bars) mice. Amino acid levels are shown as mole percentage of each amino acid per total free amino acids expressed per the average of all WT samples of the same age. Data are expressed as means \pm SEM. $n=6$ to 8 mice of each genotype of each age (A-D). ${ }^{*} P<0.05$. Cysta, cystathionine; Gly, glycine; His, histidine; Met, methionine; Ser, serine; Thr, threonine.

weeks of age, but appeared to normalize at 5 weeks of age, at which point only a slight reduction in glycine and an increase in histidine levels were observed (Figure 4, C and D).

Next, we measured the expression levels of key enzymes of serine and one-carbon metabolism (Figure 5A). L-serine is mostly synthesized de novo from the glycolytic intermediate 3-phosphoglycerate by sequential action of 3-phosphoglycerate dehydrogenase, phosphoserine aminotransferase, and phosphoserine phosphatase in astrocytes. The expression of these enzymes was unchanged in $\mathrm{Npcl}^{-1-}$ cerebellum and hippocampus at 5 weeks of age (Figure 5, $\mathrm{B}-\mathrm{D}$ ), whereas at 3 weeks, 3-phosphoglycerate dehydrogenase and phosphoserine aminotransferase mRNA levels were decreased (Figure 5, B and C). The expression of the degradative enzymes D-amino oxidase, serine dehydratase, and glycine dehydrogenase was unchanged in $\mathrm{Npcl}^{-1-}$ cerebellum (Figure 5, E-G). In $\mathrm{Npcl}^{-1-}$ hippocampus, serine dehydratase mRNA levels were increased at 3 weeks of age $\left(1.6 \pm 0.19\right.$-fold, $\mathrm{Npcl}^{-1-}$ versus WT; data not shown), and D-amino oxidase mRNA levels were increased at 5 weeks of age (Figure 5E), although hippocampal D-amino oxidase mRNA levels were overall low, consistent with previous reports. ${ }^{37}$ In one-carbon metabolism, dihydrofolate reductase and cytosolic serine methyltransferase (SHMT1), but not mitochondrial SHMT2, showed significantly decreased mRNA levels in $\mathrm{Npcl}^{-1-}$ cerebellum at 3 and 5 weeks of age (Figure 5, H-J). Thymidylate synthase mRNA levels were increased in $\mathrm{Npcl}^{-1-}$ cerebellum at 5 weeks of age
(Figure 5K). Expression of methylene tetrahydrofolate dehydrogenases (1 and 2) was not significantly altered (data not shown). Methylene tetrahydrofolate reductase mRNA levels were decreased in $\mathrm{Npcl}^{-1-}$ cerebellum at 3 weeks of age, whereas methionine synthase mRNA levels were unchanged (Figure 5, L and $\mathrm{M}$ ). Methionine adenosyltransferase 2 (MAT2A) mRNA levels were decreased in $\mathrm{Npcl}^{-1-}$ cerebellum at 3 weeks of age (Figure $5 \mathrm{~N}$ ), and mRNA levels of the regulatory subunit of MAT2, which renders the enzyme susceptible to product inhibition by S-AdoMet, ${ }^{38}$ were decreased at 5 weeks of age (Figure 5O). No changes were observed in cystathionine synthase expression (Figure 5P). In $\mathrm{Npcl}^{-1-}$ hippocampus, gene expression related to one-carbon metabolism was largely unaltered with the exception of an increase in MAT2A mRNA levels at 5 weeks of age (Figure $5 \mathrm{~N}$ ).

\section{De Novo DNA Methyltransferase mRNA Levels and Global DNA Hypomethylation Decreases in Presymptomatic $\mathrm{NpC1}^{-/-}$Cerebellum}

Folate and methylation cycles provide one-carbon units for DNA methylation and thus influence the epigenetic regulation of gene expression. Therefore, we explored potential alterations in DNA methylation by measuring mRNA levels of DNA methyltransferases and methyl-CpG-binding protein as well as global DNA methylation in $\mathrm{Npcl}^{-1-}$ cerebellum and hippocampus. In $\mathrm{NpCl}^{-1-}$ cerebellum, mRNA levels of the de novo DNA methyltransferase 3a (DNMT3A), methyl-CpG-binding protein 

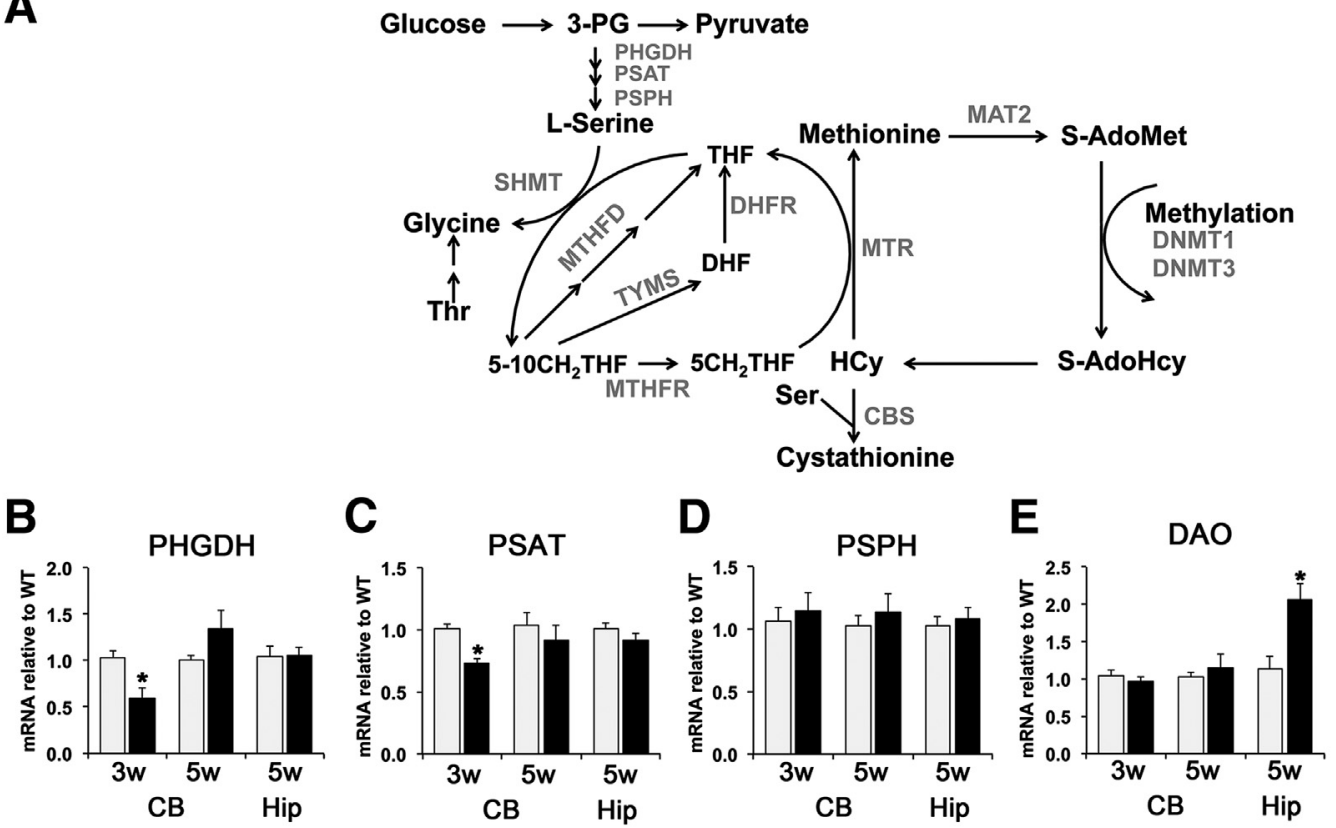

$\mathbf{F}$
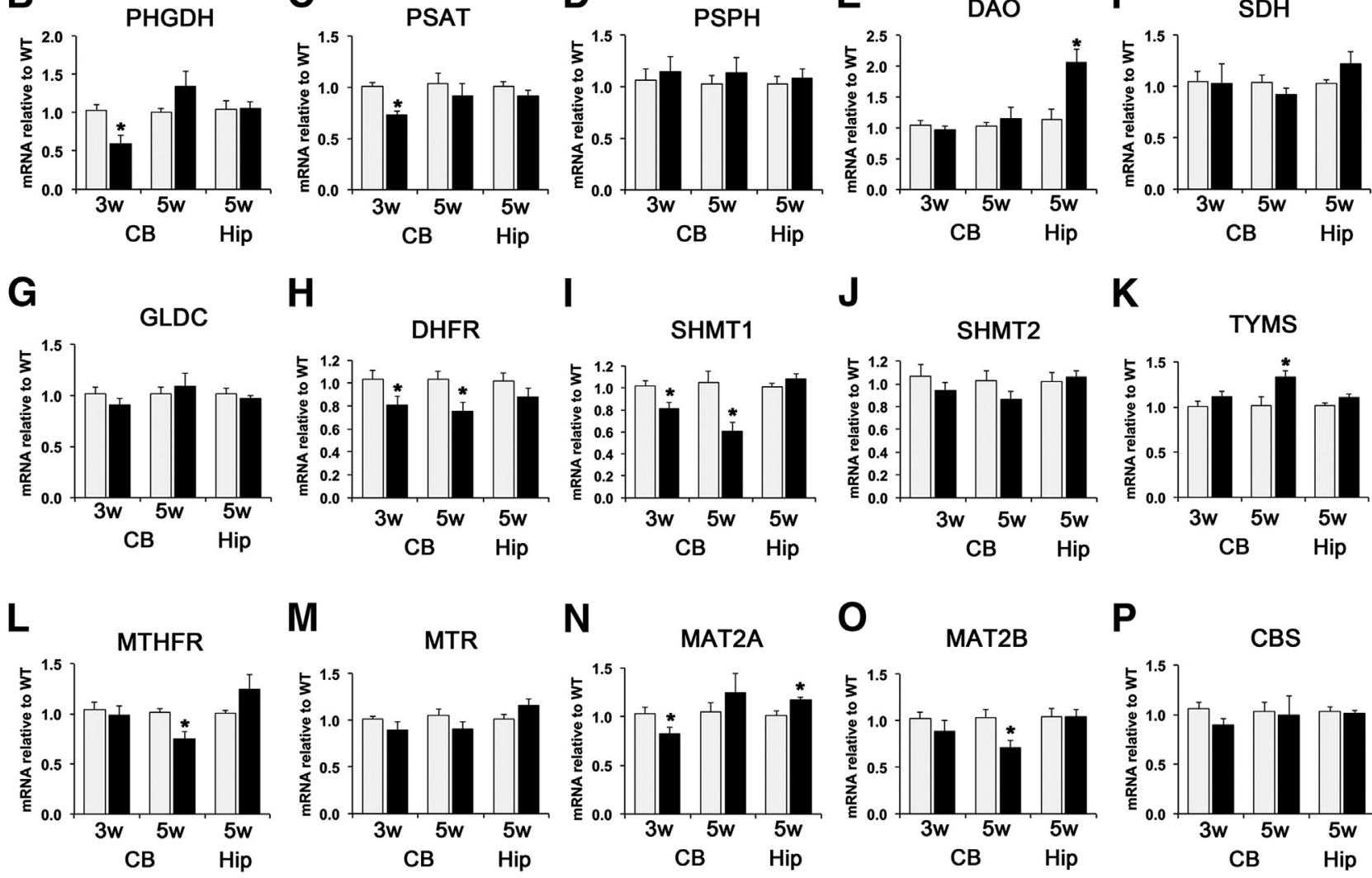

Figure 5 Expression of key enzymes of one-carbon metabolism in $\mathrm{NpC1}^{-/-}$cerebellum and hippocampus. A: Overview of main pathways of one-carbon metabolism (folate and methylation cycles). B-P: RNA extracts were prepared from snap-frozen cerebella (CB) and hippocampi (Hip) of 3- or 5-week-old wild-type (WT, white bars) and Npc1-1- (black bars) mice and mRNA levels of the indicated target genes were analyzed by real-time quantitative PCR using cyclophilin as housekeeping gene. Data are expressed as means \pm SEM $(\mathbf{B}-\mathbf{P}) .{ }^{*} P<0.05$. DHF, dihydrofolate; HCy, homocysteine; SAdoHCy, S-adenosylhomocysteine; SAdoMet, S-adenosylmethionine; THF, tetrahydrofolate; $5-\mathrm{CH}_{2} \mathrm{THF}$, methyl THF; 5-10 $\mathrm{CH}_{2} \mathrm{THF}$, methylene THF.

2 (MECP2), and methyl-CpG-domain-binding protein 2 were significantly decreased at 3 weeks of age, whereas the expression of the maintenance DNMT1, DNMT3B, and catechol-Omethyltransferase was unchanged (Figure 6A). At 5 weeks of age, the expression of DNA methyltransferases and methylCpG-binding proteins in $\mathrm{Npcl}^{-/-}$cerebellum was no longer different from WT (Figure 6B). $N p c 1^{-1-}$ hippocampus showed no differences in DNMT3A or methyl-CpG binding domains, but a strong trend to increased DNMT3B mRNA levels at 3 weeks of age (Figure 6C) and increased DNMT1 and DNMT3B mRNA levels at 5 weeks of age (Figure 6D).
To determine whether the differences in gene expression were associated with alterations in DNA methylation, and which cell types (PCs, neurons, or astrocytes) were most affected, we performed immunofluorescence staining of cerebellar slices of 3-week-old mice with antibodies against 5-mC, calbindin (PCs), NeuN (neuronal nuclei), and GFAP (astrocytes), in conjunction with DAPI staining (Figure 7). Consistent with previous reports, 5-mC labeling was distributed throughout the nuclei, with punctate pockets of condensed heterochromatin that were also visible by DAPI staining. ${ }^{39}$ Among the three layers of the cerebellar 
A

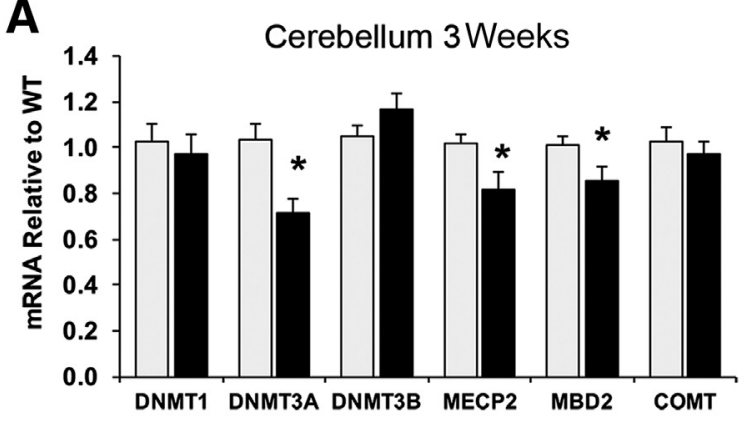

C

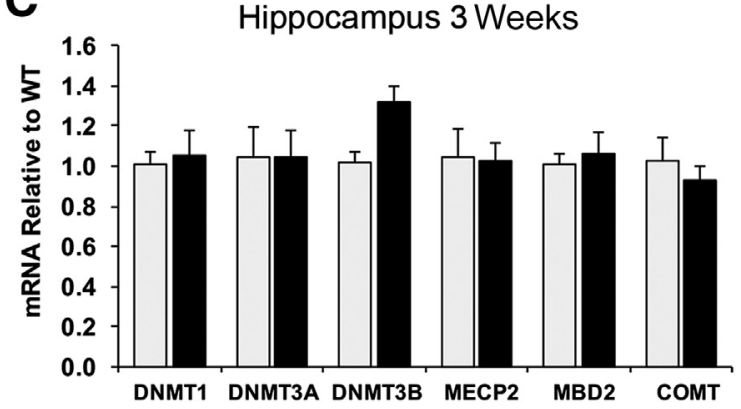

B

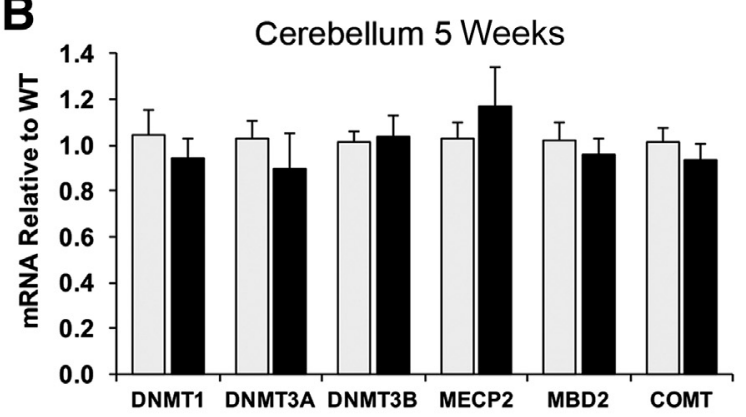

D

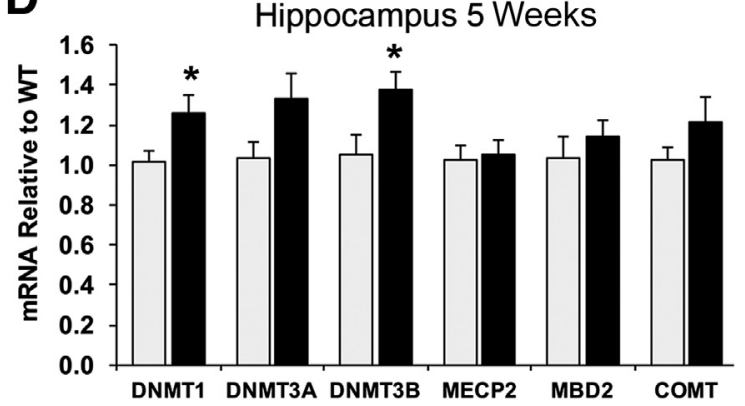

Figure 6 Altered expression of DNA methyltransferase (DNMT) 3a and methyl-CpG-domain binding proteins (MBDs) in Npc1 ${ }^{-1-}$ cerebellum. RNA extracts were prepared from snap-frozen cerebella and hippocampi of 3- or 5-week-old wild-type (WT, white bars) and Npc1-1- (black bars) mice and the mRNA levels of the indicated target genes were analyzed by real-time quantitative PCR using cyclophilin as housekeeping gene. Cerebellum at 3 (A) and 5 (B) weeks. Hippocampus at 3 (C) and 5 (D) weeks. Data are expressed as means \pm SEM. ${ }^{*} P<0.05$. COMT, catechol-0-methyltransferase; MECP, methyl-CpG-binding protein 2.

cortex-GL, PCL, and ML-the most abundant 5-mC staining was seen in the GL, and similar to NeuN staining (Figure 7, A-C), reflecting the high number of small cerebellar granule neurons in the GL. Nuclei in the ML appeared relatively bright in the 5-mC fluorescence and were mostly NeuN negative. GFAP staining showed no overlap with 5-mC fluorescence (Figure 7, D-F). Calbindin staining was visible in PC cell bodies and dendrites reaching into the ML, and appeared to show some overlap with 5-mC fluorescence in PCL (Figure 7, G-I). Higher-magnification images showed relatively weak 5 -mC staining in nuclei of calbindin-positive $\mathrm{PC}$ and brighter 5-mC staining in the surrounding nuclei in the PCL in both WT and $\mathrm{Npcl}^{-1-}$ slices (Figure 8, A-H). Many of the brightly stained nuclei in the PCL were NeuN negative (Figure 8, I-L), consistent with the known presence of Bergmann glia in the PCL. To
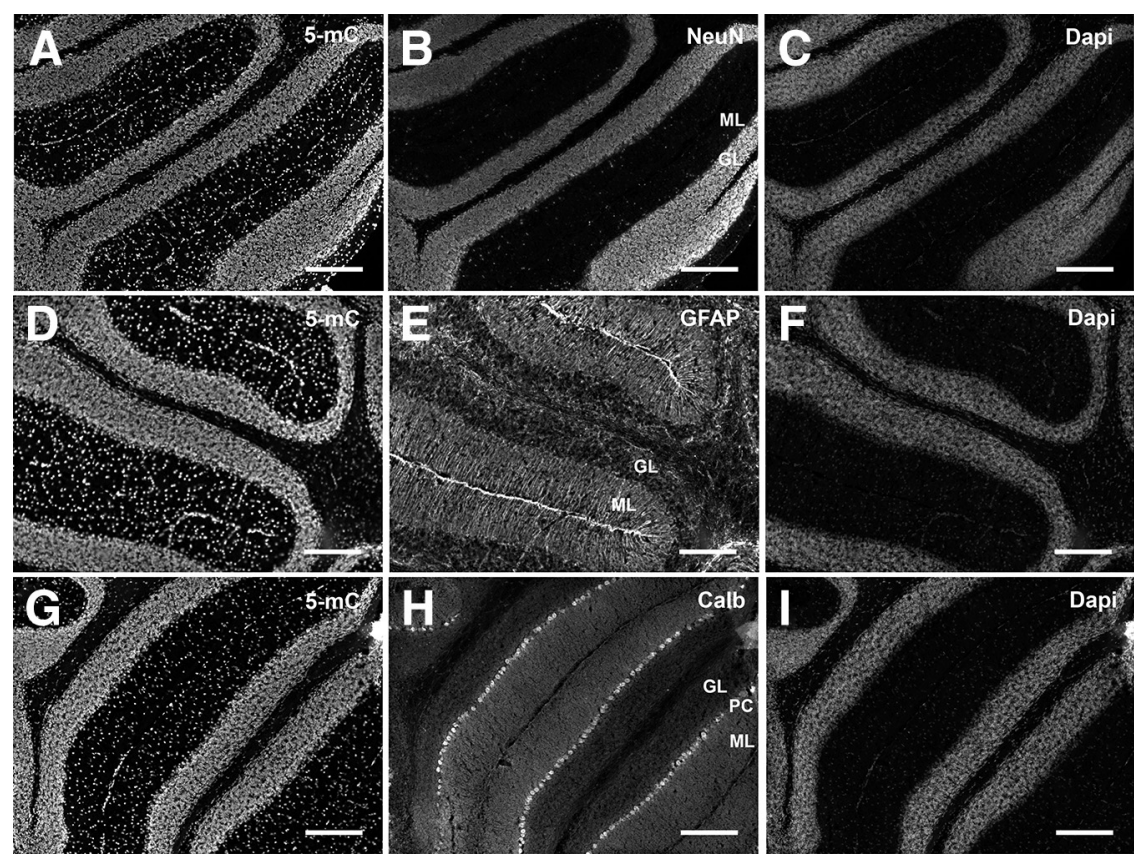

Figure 7 Distribution of 5-methylcytosine (5-mC) immunoreactivity in the cerebellum. Cerebellar slices prepared from 3-week-old wild-type mice were stained with antibodies directed against $5-\mathrm{mC}$ in combination with antibodies against NeuN $(\mathbf{A}-\mathbf{C})$, glial fibrillary acidic protein (GFAP) (D-F), or calbindin (Calb) (G-I) and stained with DAPI. Images were acquired with a $10 \times$ objective. Scale bars $=200 \mu \mathrm{m}(\mathbf{A}-\mathbf{I}) . \mathrm{GL}$, granular layer; ML, molecular layer; PC, Purkinje cell. 

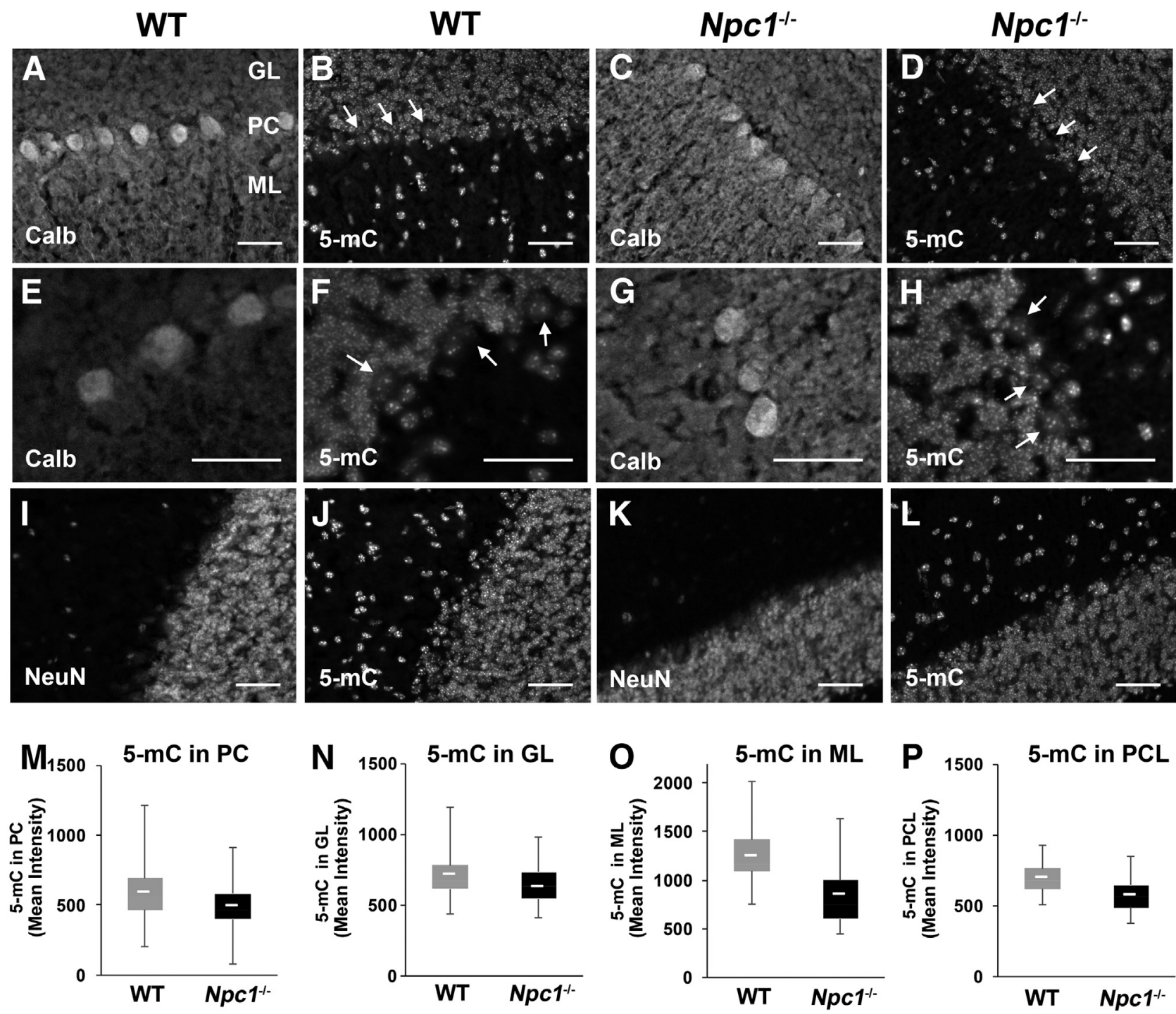

Figure 8 5-Methylcytosine $(5-\mathrm{mC})$ fluorescence in Purkinje cells and different layers of 3-week-old wild-type (WT) and Npc1 ${ }^{-/-}$cerebellum. A-H: Cerebellar slices prepared from 3-week-old WT (A, B, E, and F) and $\mathrm{Npc1}^{-/-}(\mathbf{C}, \mathbf{D}, \mathbf{G}$, and $\mathbf{H})$ mice were stained with antibodies against 5-mC and calbindin (Calb). Images were acquired with constant exposure settings using a $20 \times(\mathbf{A}-\mathbf{D})$ or $40 \times(\mathbf{E}-\mathbf{H})$ objective. White arrows indicate Purkinje cell nuclei. I-L: Cerebellar slices prepared from 3-week-old WT (I and $\mathbf{J})$ and $\mathrm{Npc1}^{-1-}(\mathbf{K}$ and $\mathbf{L})$ mice were stained with antibodies against 5-mC and NeuN. Images were acquired with constant exposure settings using a $20 \times$ objective. Images are shown at the same brightness/contrast settings for each antibody stain. $\mathbf{M}-\mathbf{P}$ : Box and whisker plots of the means and distribution of the 5-mC fluorescence intensity in Purkinje cell bodies (PC) (M), in the granular layer (GL) (N), the molecular layer $(\mathrm{ML})(\mathbf{0})$, and the Purkinje cell layer $(\mathrm{PCL})(\mathbf{P})$. Ten images were analyzed per mouse, with three mice for each genotype. For $\mathrm{ML}$, $\mathrm{GL}$, and $\mathrm{PCL}$ fluorescence intensities of all regions of interest of one image were averaged to one data point. Box boundaries indicate the upper and lower quartile; white lines indicate the mean; error bars indicate the highest and lowest value (M-P). Scale bars $=40 \mu \mathrm{m}$.

assess potential differences in DNA methylation between WT and $\mathrm{Npcl}^{-1-}$ cerebellum, we analyzed 5-mC fluorescence intensity in individual PC nuclei, and in nuclei of the ML, GL, and PCL (Figure 8, M-P). The 5-mC staining in $\mathrm{PC}$ and in the GL was not significantly different between WT and $\mathrm{Npcl}^{-1-}$ slices, although there was a trend to lower fluorescence intensities in $\mathrm{Npcl}^{-/-}$cerebellum (Figure 8, M and $\mathrm{N}$ ). Nuclei in the ML and PCL showed consistently less intense 5-mC staining in $\mathrm{Npcl}^{-1-}$ compared with WT cerebellar slices (Figure 8, O and P), suggesting that glia cells have lower levels of 5-mC.
DNA hypomethylation can occur in repetitive nonpromoter regions and lead to chromosomal instability and global effects on transcription. In addition, DNA methylation of $\mathrm{CpG}$ islands in $5^{\prime}$ regulatory regions of many genes is a key mechanism of the epigenetic regulation of individual genes. In gene promoter regions, both hypomethylation and hypermethylation are possible. For a closer investigation of the nature of the changes in DNA methylation in $\mathrm{Npcl}^{-1-}$ cerebellum, we first measured the levels of 5-mC and 5-hmC per total cytosine (C) in a repetitive non-promoter DNA sequence (mouse LINE-1 type-Gf $5^{\prime}$ untranslated region). LINE-1 

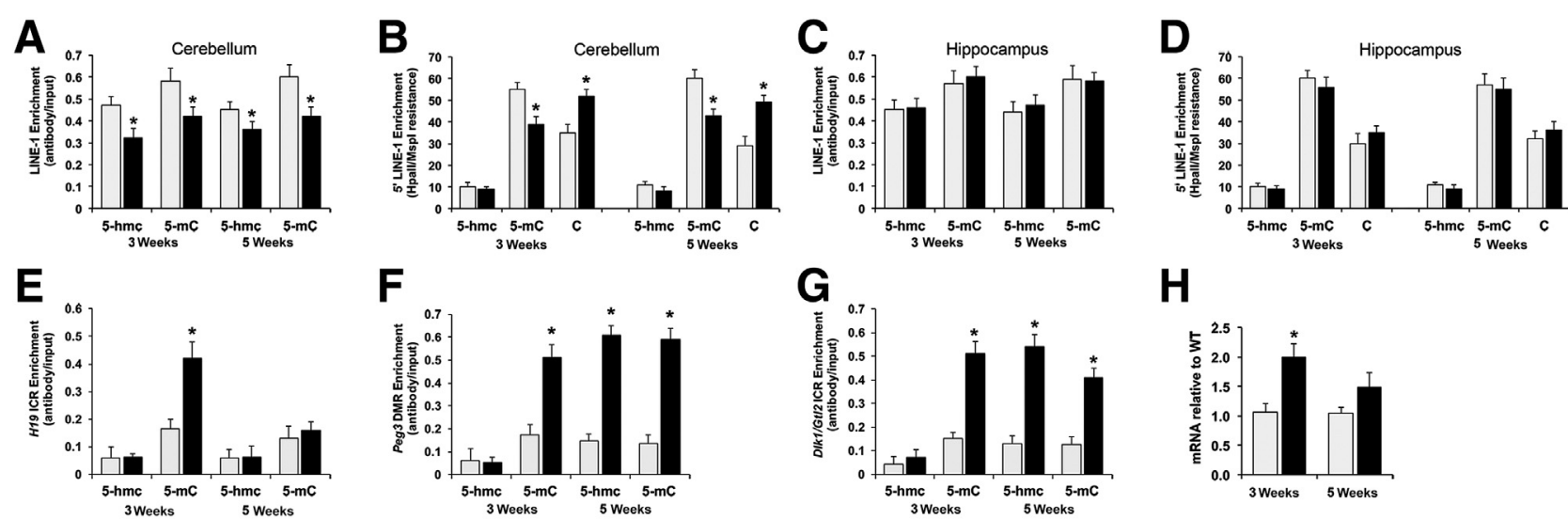

H
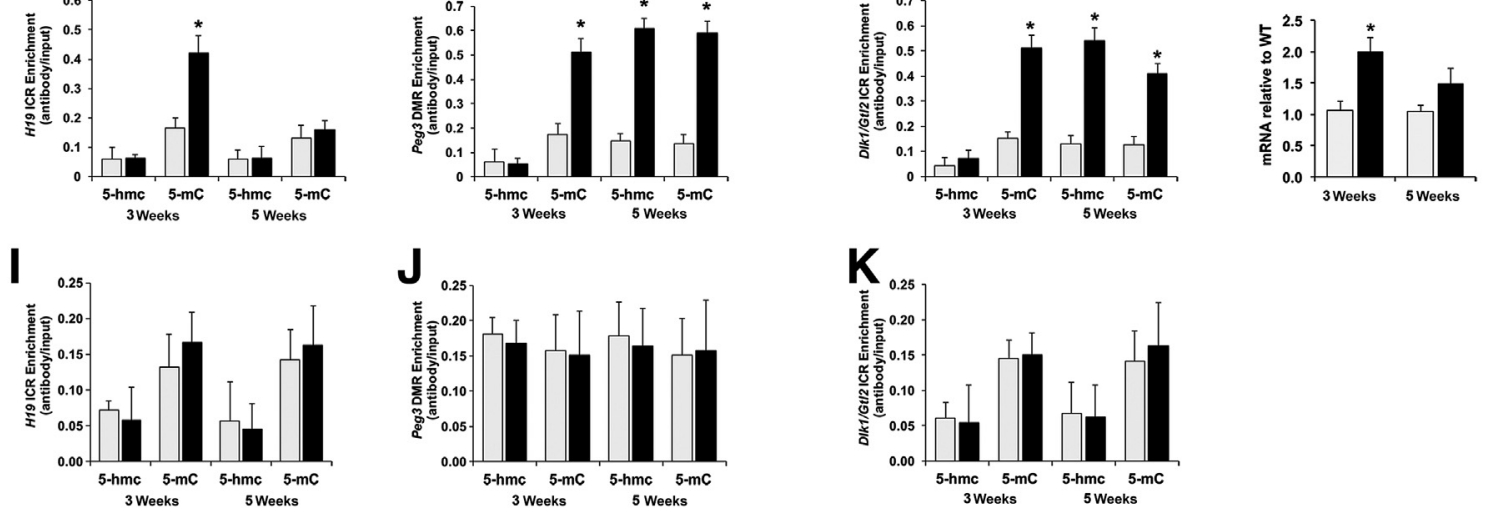

Figure 9 Hypermethylation of specific promoter regions in $\mathrm{Npc1}^{-/-}$cerebellum. Genomic DNA was isolated from snap-frozen cerebella and hippocampi of 3- or 5-week-old wild-type (WT, white bars) and $\mathrm{NpC1}^{-1-}$ (black bars) mice. A-D: 5-Methylcytosine (5-mC) and 5-hydroxymethylcytosine (5-hmC) content was determined in the LINE-1 type-Gf $5^{\prime}$ untranslated region (UTR) by chromatin immunoprecipitation (ChIP) (A and $\mathbf{C}$ ) or by restriction enzyme-based assay together with unmodified cytosine (C) (B and $\mathbf{D})$ in cerebellum ( $\mathbf{A}$ and $\mathbf{B})$ and hippocampus (C and $\mathbf{D})$ at 3 and 5 weeks of age. $\mathbf{E}-\mathbf{G}$ : 5 -mC and 5-hmC content was determined by ChIP in cerebellar DNA extracts for the $H 19$ imprinting control region (ICR) (E), the Peg3 differentially methylated region (DMR) (F), and the Dlk1/Glt2 region (G). H: Insulin-like growth factor 2 mRNA levels were analyzed in WT and Npc1 ${ }^{-1-}$ cerebellum by real-time quantitative PCR using cyclophilin as housekeeping gene. I-K: 5-mC and 5-hmC content was determined by ChIP in hippocampal DNA extracts for the H19 ICR (I), the Peg3 DMR (J), and the $D l k 1 / G l t 2$ region $(\mathbf{K})$. Data are expressed as means \pm SEM. ${ }^{*} P<0.05$.

methylation has been used extensively as a surrogate marker for global DNA methylation. ${ }^{40}$ Two different methods to determine 5-mC and 5-hmC, namely ChIP with primary antibodies against 5-mC or 5-hmC, followed by qPCR analysis (Figure 9A), and methylation-sensitive PCR of glucosylated genomic DNA (Figure 9B), revealed a striking decrease in 5$\mathrm{mC}$ content in the LINE-1 elements in $\mathrm{Npcl}^{-l-}$ cerebellum at 3 and 5 weeks of age, indicating global DNA hypomethylation. In contrast, LINE-1 5-mC and 5-hmC levels were unchanged in $\mathrm{Npcl}^{-1-}$ hippocampus (Figure 9, C and D). The levels of 5-hmC, which is a transient signal formed during active DNA demethylation and present in LINE-1 elements at much lower levels than 5-mC, appeared decreased in $\mathrm{Npcl}^{-1-}$ cerebellum when measured by ChIP, but not by restriction digest analysis (Figure 9, A and B), respectively, possibly because of different sensitivities of the methods used.

Next, we analyzed 5-mC and 5-hmC levels in three distinct loci that are known to be differentially methylated and imprinted in WT and $\mathrm{Npcl}^{-1-}$ cerebellum and hippocampus at 3 and 5 weeks of age. In the H19/Igf2 locus, an ICR associated with a 2-kb DMR upstream of $H 19$ regulates the reciprocal expression of insulin-like growth factor 2 (IGF2) and H19. ${ }^{41}$ Hypomethylation of the DMR on the maternal allele blocks enhancer-driven Igf2 transcription. $\mathrm{Peg} 3$, which is normally highly expressed in murine brain, ${ }^{42}$ is silenced by hypermethylation of the Peg3 domain ICR. ${ }^{43}$ Complete methylation of the Peg3 domain and subsequent loss of Peg 3 expression has been observed in several types of cancer. ${ }^{44}$ Dlkl and Gtl2 are reciprocally imprinted genes on mouse chromosome 12 , with hypermethylation of the DMR on the paternal and hypomethylation on the maternal allele. $^{45,46}$ ChIP analysis of 5-mC modification revealed hypermethylation of all three DMR loci in $\mathrm{Npcl}^{-1-}$ cerebellum at 3 weeks of age (Figure 9, E-G). The Peg3 and the $D l k l / G t l 2$ ICR domains were also hypermethylated in $\mathrm{NpCl}^{-1-}$ cerebellum at 5 weeks of age (Figure 9, F and G). Concomitantly, IGF2 mRNA levels were significantly increased (Figure 9H), as expected when the H19 ICR is hypermethylated. No changes in the methylation profiles of these genetic regions were observed in $\mathrm{Npcl}^{-1-}$ hippocampus (Figure 9, I-K). Thus, epigenetic changes in $\mathrm{NpCl}^{-1-}$ cerebellum include genome-wide hypomethylation and hypermethylation of specific gene promoter regions involved in tissue-specific and developmental regulation of metabolism and growth in the cerebellum.

Overall, our findings showed that NPC1 deficiency was associated with epigenetic changes in the cerebellum that could alter gene transcription and affect development and neurological function.

\section{Discussion}

In addition to the characteristic endosomal cholesterol accumulation, NPC1 deficiency is associated with a wide range of cellular abnormalities that potentially contribute to disease pathology. Herein, we describe alterations in central 
glutamine/glutamate metabolism, disturbances of folate and methylation pathways, and global DNA hypomethylation in presymptomatic and early symptomatic $\mathrm{Npcl}^{-/-}$cerebellum. This is the first report of alterations in amino acid metabolism and DNA methylation in a disorder primarily connected to cholesterol trafficking.

\section{Glutamine/Glutamate Metabolism}

The brain has one of the highest metabolic rates in the body and uses almost exclusively glucose as an energy source. Neurons rely heavily on mitochondrial oxidative metabolism of pyruvate, which is derived from glucose through glycolysis or the pentose phosphate pathway, or from lactate or alanine. Recent studies suggest impaired oxidation of pyruvate to acetyl-CoA in murine $\mathrm{Npcl}^{-/-}$cerebellum at early stages of NPC disease, ${ }^{12,16}$ which would limit the full oxidation of glucose carbons in the Krebs' cycle. When glucose oxidation is insufficient, amino acids and, in particular, glutamine/glutamate become valuable energy substrates. The increased expression of glutamine synthetase in $\mathrm{Npcl}^{-/-}$cerebellum, as observed in this study (Figure 1C), in combination with the increased pyruvate carboxylase expression found in a previous study, ${ }^{12}$ could enable astrocytes to increase de novo glutamine synthesis from glucose and provide neurons with sufficient glutamine to maintain the levels of neurotransmitter glutamate and oxidize glutamate in the Krebs' cycle. Although steady-state analyses cannot yield proof for changes in pathway activity, the alterations in amino acid metabolism observed in $\mathrm{Npcl}^{-/-}$cerebellum, in particular the elevated BCAA and asparagine levels and the increased expression of BCAT1 and AST2, are consistent with increased glutamine/ glutamate oxidation in a truncated Krebs' cycle and conversion of the resulting aspartate to asparagine, as shown in Figure 1B. The activation of glutamine oxidation through this pathway has previously been described for neurons during hypoglycemia, ${ }^{47-50}$ and prolongs neuronal survival under these conditions. ${ }^{48}$ Given that glutaminases, BCAT1, and AST2 are mainly neuronal enzymes in normal brain, ${ }^{51}$ whereas astrocytes are net producers of glutamine, it seems likely that glutamine oxidation would be mostly up-regulated in neurons in $\mathrm{Npcl}^{-1-}$ cerebellum, and be supported by increased glutamine transport from astrocytes. Moreover, our immunohistochemical analyses showed decreased PDH levels in neurons, including PCs, supporting our hypothesis of deficient neuronal pyruvate oxidation and up-regulation of compensatory pathways. Neuronal glutamine oxidation, if active, could prevent acute energy deficits in $\mathrm{Npcl}^{-/-}$cerebellum $^{48}$; however, chronic adaptations in glutamine metabolism could have detrimental consequences for ammonium and neurotransmitter homeostasis.

\section{One-Carbon Metabolism and Methylation}

Amino acid profiling revealed significant increases in the levels of serine, methionine, and other amino acid intermediates of one-carbon metabolism in $\mathrm{Npcl}^{-/-}$cerebellum. Brain serine levels are largely controlled by astrocytic de novo synthesis of L-serine from the glycolytic intermediate 3-phosphoglycerate. ${ }^{52,53}$ The increased serine levels in $\mathrm{NpCl}^{-/-}$cerebellum suggested a diversion of glycolytic intermediates into serine synthesis, consistent with the previously reported impaired pyruvate oxidation and increased lactate formation in $\mathrm{Npcl}^{-/-}$cerebellum. ${ }^{12}$ In $\mathrm{Npcl}^{-1-}$ hippocampus, where lactate levels are normal, ${ }^{12}$ we observed increases in serine only at 3 weeks, but not at 5 weeks of age (Figure 3, A and B). L-serine is a neurotrophic factor and the precursor for the NMDA receptor coagonist D-serine, which modulates excitatory neurotransmission. ${ }^{54,55}$ In addition, serine is a main source of activated one-carbon units for folate- and S-AdoMetdependent methyl transfer reactions. The increase in serine and methionine together with the altered expression of SHMT1, dihydrofolate reductase, thymidylate synthase, and MAT2 indicated early disturbances of folate and methylation pathways in $\mathrm{Npcl}^{-/-}$cerebellum, although the exact nature of the alterations in one-carbon metabolism is still unknown. Cytosolic SHMT1 preferentially directs onecarbon units into de novo thymidylate synthesis and decreases the availability of 5-methyl-tetrahydrofolate for the methionine cycle and S-AdoMet synthesis. ${ }^{56-58}$ Accordingly, SHMT1-deficient mice show impaired thymidylate synthesis, altered thymidylate synthase expression, and, in some models, increased S-AdoMet levels. ${ }^{56-59} \mathrm{Shmtl}^{+/-}$ mice develop cognitive impairments because of impaired thymidylate synthesis. ${ }^{56}$ Similar metabolic effects might occur in $\mathrm{Npcl}^{-1-}$ cerebellum. In view of the apparent overabundance of methionine and other one-carbon donors, the finding of lower 5-mC immunoreactivity and global DNA hypomethylation in $\mathrm{Npcl}^{-1-}$ cerebellum seemed unexpected. DNA hypomethylation is most commonly observed in connection with an insufficient availability of methionine because of dietary deficiencies in folate, methionine, and/or choline. ${ }^{60-62}$ However, even hypermethioninemias because of excess dietary methionine without genetic defects are not clearly associated with global DNA hypermethylation, ${ }^{63,64}$ although hypermethylation of specific promoter elements after methionine supplementation can occur. ${ }^{65}$ On the other hand, the decreased expression of MAT2A and DNMT3A in $\mathrm{Npcl}^{-1-}$ cerebellum (Figures 5 and 6) could impair adenosylation and/or methylation and thus contribute to the observed methionine accumulation and global DNA hypomethylation. The hypomethylation of LINE-1 elements persisted in $\mathrm{Npcl}^{-1-}$ cerebellum at 5 weeks of age, although MAT2A and DNMT3A expression was normal and methionine levels were still elevated. One possible explanation is that DNMT3A and DNMT3B exhibit nonoverlapping functions early in development, and that other epigenetic machinery, including DNMT3B, maintains the methylation pattern of LINE-1 elements in later stages. Moreover, genome-wide analysis has revealed that methylation 
patterns of $\mathrm{CpG}$ islands in certain promoter regions of single genes are more dynamic than repetitive LINE-1 sequences. ${ }^{66}$ DNMT3A is not only important during early neurodevelopment, but also dynamically regulates DNA methylation in postmitotic neurons for memory formation and synaptic plasticity. ${ }^{67-71}$ The altered expression of the methylated DNA-binding proteins MECP2 and methylCpG-domain-binding protein 2 in $\mathrm{Npcl}^{-/-}$cerebellum at 3 weeks (Figure 6) suggests that, in addition to DNA methylation itself, the cellular interpretation of the methylation pattern may be disturbed. MECP2 regulates chromatin structure and gene expression by binding to $5-\mathrm{mC}$ and 5$\mathrm{hmC} .{ }^{72}$ Mutations in MECP2 cause Rett syndrome, a neurodevelopmental disorder with severe cognitive impairment, motor deficits, and other neurological symptoms. ${ }^{73,74}$ Even when induced postnatally, MECP2 deficiency causes severe neurological defects, impaired synaptic plasticity, and dendritic spine formation in vivo and in cultured neurons. ${ }^{75,76}$

The mechanisms leading to brain region-specific changes in gene expression and DNA methylation in $\mathrm{NpCl}^{-1-}$ cerebellum, and which cell types are most affected are still unclear. Immunohistochemistry indicated decreased 5-mC levels in nonneuronal nuclei in the ML and PCL, but no significant changes in PCs or in the GL. Given the distribution of 5-mC staining in the cerebellum with highest levels in the GL, and the high numerical abundance of granule neurons, it seems unlikely that the alterations in DNA methylation, which we observed in total DNA extracts, are completely because of glia. Given that the lack of significant changes in total, immunoreactive 5-mC could also partly be because of the combination of hypomethylation and hypermethylation of different DNA elements, we cannot exclude that DNA methylation is also altered in $\mathrm{Npcl}^{-1-}$ Purkinje and granule neurons. However, further investigation is required to unequivocally answer this question. Regardless of their origin and exact location, the observed epigenetic changes could contribute to NPC neuropathology. LINEs represent the most abundant autonomous retrotransposons in the mammalian genome and are silenced by DNA methylation. ${ }^{77}$ Derepression of LINE-1 elements because of DNA demethylation contributes to the development of chromosomal abnormalities and genomic instability and is a source of genome-wide gene expression dysregulation. ${ }^{78-81}$ LINE-1 promoters can drive transcription of noncoding RNAs that participate in targeted gene silencing through chromatin remodeling. ${ }^{82}$ Although LINE-1 sequences represent a large portion of the mammalian genome and their methylation levels are pathological hallmarks of a wide spectrum of neurological conditions, ${ }^{83}$ LINE-1 methylation is not always reflective of site-specific methylation outside of repetitive sequences, which can affect the expression of specific genes. ${ }^{84,85}$ Herein, we found hypermethylation of the DMR of three different genetic loci in $\mathrm{NpCl}^{-1-}$ cerebellum, and hypermethylation of the H19 ICR was associated with increased mRNA levels of IGF2 at 3 weeks of age (Figure 9). We chose these three loci on the basis of their well-characterized methylation patterns as markers for promoter methylation rather than a potential relevance of their gene products for NPC disease, and cannot speculate on possible consequences of differential gene expression in these regions. However, the aberrant epigenetic regulation of individual genes adds another layer of complexity to NPC pathology.

Overall, our findings reveal previously unknown alterations in amino acid and one-carbon metabolism and in DNA methylation in murine NPC1-deficient brain. Alterations in these pathways can have far-reaching functional consequences, such as changes in neurotransmitter and nitrogen homeostasis and in the epigenetic regulation of gene expression. The presymptomatic appearance of these changes makes it likely that they are pathogenic mechanisms contributing to neurological decline and neurodegeneration in NPC disease. Deeper insight into the role of metabolic aberrations and epigenetic regulation of gene expression in NPC1-deficient brain may open the door to additional treatment options.

\section{Acknowledgments}

We thank Debra Fice for technical help and Rey Interior (Hospital for Sick Children, Toronto, ON, Canada) for conducting the amino acid analyses.

\section{Supplemental Data}

Supplemental material for this article can be found at http://dx.doi.org/10.1016/j.ajpath.2016.02.012.

\section{References}

1. Ory DS: The Niemann-Pick disease genes: regulators of cellular cholesterol homeostasis. Trends Cardiovasc Med 2004, 14: $66-72$

2. Vance JE, Peake KB: Function of the Niemann-Pick type C proteins and their bypass by cyclodextrin. Curr Opin Lipidol 2011, 22: 204-209

3. Ikonen E, Holtta-Vuori M: Cellular pathology of Niemann-Pick type C disease. Semin Cell Dev Biol 2004, 15:445-454

4. Karten B, Peake KB, Vance JE: Mechanisms and consequences of impaired lipid trafficking in Niemann-Pick type C1-deficient mammalian cells. Biochim Biophys Acta 2009, 1791:659-670

5. Vanier MT: Niemann-Pick diseases. Handb Clin Neurol 2013, 113: $1717-1721$

6. Vance JE, Karten B: Niemann-Pick C disease and mobilization of lysosomal cholesterol by cyclodextrin. J Lipid Res 2014, 55: 1609-1621

7. Mondjinou YA, McCauliff LA, Kulkarni A, Paul L, Hyun SH, Zhang Z, Wu Z, Wirth M, Storch J, Thompson DH: Synthesis of 2-hydroxypropyl-beta-cyclodextrin/pluronic-based polyrotaxanes via heterogeneous reaction as potential Niemann-Pick type $\mathrm{C}$ therapeutics. Biomacromolecules 2013, 14:4189-4197

8. Ottinger EA, Kao ML, Carrillo-Carrasco N, Yanjanin N, Shankar RK, Janssen M, Brewster M, Scott I, Xu X, Cradock J, 
Terse P, Dehdashti SJ, Marugan J, Zheng W, Portilla L, Hubbs A, Pavan WJ, Heiss J, Vite CH, Walkley SU, Ory DS, Silber SA, Porter FD, Austin CP, McKew JC: Collaborative development of 2-hydroxypropyl-beta-cyclodextrin for the treatment of NiemannPick type C1 disease. Curr Top Med Chem 2014, 14:330-339

9. Rosenbaum AI, Maxfield FR: Niemann-Pick type C disease: molecular mechanisms and potential therapeutic approaches. J Neurochem 2011, 116:789-795

10. Helquist P, Maxfield FR, Wiech NL, Wiest O: Treatment of Niemann-Pick type $\mathrm{C}$ disease by histone deacetylase inhibitors. Neurotherapeutics 2013, 10:688-697

11. Fu R, Yanjanin NM, Bianconi S, Pavan WJ, Porter FD: Oxidative stress in Niemann-Pick disease, type C. Mol Genet Metab 2010, 101: 214-218

12. Kennedy BE, Leblanc VG, Mailman TM, Fice D, Burton I, Karakach TK, Karten B: Pre-symptomatic activation of antioxidant responses and alterations in glucose and pyruvate metabolism in Niemann-Pick type c1-deficient murine brain. PLoS One 2013, 8: e82685

13. Fu R, Wassif CA, Yanjanin NM, Watkins-Chow DE, Baxter LL, Incao A, Liscum L, Sidhu R, Firnkes S, Graham M, Ory DS, Porter FD, Pavan WJ: Efficacy of N-acetylcysteine in phenotypic suppression of mouse models of Niemann-Pick disease, type C1. Hum Mol Genet 2013, 22:3508-3523

14. Jiang $X$, Sidhu R, Porter FD, Yanjanin NM, Speak AO, te Vruchte DT, Platt FM, Fujiwara H, Scherrer DE, Zhang J, Dietzen DJ, Schaffer JE, Ory DS: A sensitive and specific LCMS/MS method for rapid diagnosis of Niemann-Pick $\mathrm{C} 1$ disease from human plasma. J Lipid Res 2011, 52:1435-1445

15. Vazquez MC, Balboa E, Alvarez AR, Zanlungo S: Oxidative stress: a pathogenic mechanism for Niemann-Pick type C disease. Oxid Med Cell Longev 2012, 2012:205713

16. Cologna SM, Jiang XS, Backlund PS, Cluzeau CV, Dail MK, Yanjanin NM, Siebel S, Toth CL, Jun HS, Wassif CA, Yergey AL, Porter FD: Quantitative proteomic analysis of Niemann-Pick disease, type $\mathrm{C} 1$ cerebellum identifies protein biomarkers and provides pathological insight. PLoS One 2012, 7:e47845

17. Li E, Zhang Y: DNA methylation in mammals. Cold Spring Harb Perspect Biol 2014, 6:a019133

18. Suzuki MM, Bird A: DNA methylation landscapes: provocative insights from epigenomics. Nat Rev Genet 2008, 9:465-476

19. Okano M, Bell DW, Haber DA, Li E: DNA methyltransferases Dnmt3a and Dnmt3b are essential for de novo methylation and mammalian development. Cell 1999, 99:247-257

20. Li E, Bestor TH, Jaenisch R: Targeted mutation of the DNA methyltransferase gene results in embryonic lethality. Cell 1992, 69: 915-926

21. Sharif J, Muto M, Takebayashi S, Suetake I, Iwamatsu A, Endo TA, Shinga J, Mizutani-Koseki Y, Toyoda T, Okamura K, Tajima S, Mitsuya K, Okano M, Koseki H: The SRA protein Np95 mediates epigenetic inheritance by recruiting Dnmt1 to methylated DNA. Nature 2007, 450:908-912

22. Tate PH, Bird AP: Effects of DNA methylation on DNA-binding proteins and gene expression. Curr Opin Genet Dev 1993, 3:226-231

23. Blattler A, Farnham PJ: Cross-talk between site-specific transcription factors and DNA methylation states. J Biol Chem 2013, 288: 34287-34294

24. Watt F, Molloy PL: Cytosine methylation prevents binding to DNA of a HeLa cell transcription factor required for optimal expression of the adenovirus major late promoter. Genes Dev 1988, 2:1136-1143

25. Robertson KD: DNA methylation and human disease. Nat Rev Genet 2005, 6:597-610

26. Loftus SK, Morris JA, Carstea ED, Gu JZ, Cummings C, Brown A, Ellison J, Ohno K, Rosenfeld MA, Tagle DA, Pentchev PG, Pavan WJ: Murine model of Niemann-Pick C disease: mutation in a cholesterol homeostasis gene. Science 1997, 277:232-235
27. Wu H, Southam AD, Hines A, Viant MR: High-throughput tissue extraction protocol for NMR- and MS-based metabolomics. Anal Biochem 2008, 372:204-212

28. Pfaffl MW: A new mathematical model for relative quantification in real-time RT-PCR. Nucleic Acids Res 2001, 29:e45

29. Crane-Robinson C, Myers FA, Hebbes TR, Clayton AL, Thorne AW: Chromatin immunoprecipitation assays in acetylation mapping of higher eukaryotes. Methods Enzymol 1999, 304:533-547

30. Wang J, Weaver IC, Gauthier-Fisher A, Wang H, He L, Yeomans J, Wondisford F, Kaplan DR, Miller FD: CBP histone acetyltransferase activity regulates embryonic neural differentiation in the normal and Rubinstein-Taybi syndrome brain. Dev Cell 2010, 18: $114-125$

31. Voikar V, Rauvala H, Ikonen E: Cognitive deficit and development of motor impairment in a mouse model of Niemann-Pick type $\mathrm{C}$ disease. Behav Brain Res 2002, 132:1-10

32. Yudkoff M, Daikhin Y, Nelson D, Nissim I, Erecinska M: Neuronal metabolism of branched-chain amino acids: flux through the aminotransferase pathway in synaptosomes. J Neurochem 1996, 66: $2136-2145$

33. Yudkoff M: Brain metabolism of branched-chain amino acids. Glia 1997, 21:92-98

34. Rothman DL, De Feyter HM, Maciejewski PK, Behar KL: Is there in vivo evidence for amino acid shuttles carrying ammonia from neurons to astrocytes? Neurochem Res 2012, 37:2597-2612

35. Milner TA, Aoki C, Sheu KF, Blass JP, Pickel VM: Light microscopic immunocytochemical localization of pyruvate dehydrogenase complex in rat brain: topographical distribution and relation to cholinergic and catecholaminergic nuclei. J Neurosci 1987, 7: $3171-3190$

36. Lucas EK, Reid CS, McMeekin LJ, Dougherty SE, Floyd CL, Cowell RM: Cerebellar transcriptional alterations with Purkinje cell dysfunction and loss in mice lacking PGC-1alpha. Front Cell Neurosci 2015, 8:441

37. Verrall L, Walker M, Rawlings N, Benzel I, Kew JN, Harrison PJ, Burnet PW: d-Amino acid oxidase and serine racemase in human brain: normal distribution and altered expression in schizophrenia. Eur J Neurosci 2007, 26:1657-1669

38. LeGros HL Jr, Halim AB, Geller AM, Kotb M: Cloning, expression, and functional characterization of the beta regulatory subunit of human methionine adenosyltransferase (MAT II). J Biol Chem 2000, 275:2359-2366

39. Brown SE, Weaver ICG, Meaney MJ, Szyf M: Regional-specific global cytosine methylation and DNA methyltransferase expression in the adult rat hippocampus. Neurosci Letters 2008, 440: 49-53

40. Yang AS, Estecio MR, Doshi K, Kondo Y, Tajara EH, Issa JP: A simple method for estimating global DNA methylation using bisulfite PCR of repetitive DNA elements. Nucleic Acids Res 2004, 32:e38

41. Waterland RA, Lin JR, Smith CA, Jirtle RL: Post-weaning diet affects genomic imprinting at the insulin-like growth factor 2 (Igf2) locus. Hum Mol Genet 2006, 15:705-716

42. Kim J, Bergmann A, Choo JH, Stubbs L: Genomic organization and imprinting of the Peg3 domain in bovine. Genomics 2007, 90:85-92

43. He H, Kim J: Regulation and function of the peg3 imprinted domain. Genomics Inform 2014, 12:105-113

44. Maegawa S, Yoshioka H, Itaba N, Kubota N, Nishihara S, Shirayoshi Y, Nanba E, Oshimura M: Epigenetic silencing of PEG3 gene expression in human glioma cell lines. Mol Carcinog 2001, 31: $1-9$

45. Wylie AA, Murphy SK, Orton TC, Jirtle RL: Novel imprinted DLK1/GTL2 domain on human chromosome 14 contains motifs that mimic those implicated in IGF2/H19 regulation. Genome Res 2000, 10:1711-1718

46. Takada S, Paulsen M, Tevendale M, Tsai CE, Kelsey G, Cattanach BM, Ferguson-Smith AC: Epigenetic analysis of the Dlk1Gt12 imprinted domain on mouse chromosome 12: implications for 
imprinting control from comparison with Igf2-H19. Hum Mol Genet 2002, 11:77-86

47. Rao R, Ennis K, Long JD, Ugurbil K, Gruetter R, Tkac I: Neurochemical changes in the developing rat hippocampus during prolonged hypoglycemia. J Neurochem 2010, 114:728-738

48. Sutherland GR, Tyson RL, Auer RN: Truncation of the krebs cycle during hypoglycemic coma. Med Chem 2008, 4:379-385

49. Amaral AI, Teixeira AP, Sonnewald U, Alves PM: Estimation of intracellular fluxes in cerebellar neurons after hypoglycemia: importance of the pyruvate recycling pathway and glutamine oxidation. J Neurosci Res 2011, 89:700-710

50. Peng L, Gu L, Zhang H, Huang X, Hertz E, Hertz L: Glutamine as an energy substrate in cultured neurons during glucose deprivation. J Neurosci Res 2007, 85:3480-3486

51. Lovatt D, Sonnewald U, Waagepetersen HS, Schousboe A, He W, Lin JH, Han X, Takano T, Wang S, Sim FJ, Goldman SA, Nedergaard M: The transcriptome and metabolic gene signature of protoplasmic astrocytes in the adult murine cortex. J Neurosci 2007 , 27:12255-12266

52. Yang JH, Wada A, Yoshida K, Miyoshi Y, Sayano T, Esaki K, Kinoshita MO, Tomonaga S, Azuma N, Watanabe M, Hamase K, Zaitsu K, Machida T, Messing A, Itohara S, Hirabayashi Y, Furuya S: Brain-specific Phgdh deletion reveals a pivotal role for L-serine biosynthesis in controlling the level of D-serine, an N-methyl-Daspartate receptor co-agonist, in adult brain. J Biol Chem 2010, 285 : 41380-41390

53. Yamasaki M, Yamada K, Furuya S, Mitoma J, Hirabayashi Y, Watanabe M: 3-Phosphoglycerate dehydrogenase, a key enzyme for 1-serine biosynthesis, is preferentially expressed in the radial glia/astrocyte lineage and olfactory ensheathing glia in the mouse brain. J Neurosci 2001, 21:7691-7704

54. Furuya S, Tabata T, Mitoma J, Yamada K, Yamasaki M, Makino A, Yamamoto T, Watanabe M, Kano M, Hirabayashi Y: L-serine and glycine serve as major astroglia-derived trophic factors for cerebellar Purkinje neurons. Proc Natl Acad Sci U S A 2000, 97:11528-11533

55. Wolosker H: Serine racemase and the serine shuttle between neurons and astrocytes. Biochim Biophys Acta 2011, 1814: $1558-1566$

56. Abarinov EV, Beaudin AE, Field MS, Perry CA, Allen RH, Stabler SP, Stover PJ: Disruption of shmt1 impairs hippocampal neurogenesis and mnemonic function in mice. J Nutr 2013, 143:1028-1035

57. MacFarlane AJ, Liu X, Perry CA, Flodby P, Allen RH, Stabler SP, Stover PJ: Cytoplasmic serine hydroxymethyltransferase regulates the metabolic partitioning of methylenetetrahydrofolate but is not essential in mice. J Biol Chem 2008, 283:25846-25853

58. Herbig K, Chiang EP, Lee LR, Hills J, Shane B, Stover PJ: Cytoplasmic serine hydroxymethyltransferase mediates competition between folate-dependent deoxyribonucleotide and S-adenosylmethionine biosyntheses. J Biol Chem 2002, 277:38381-38389

59. Macfarlane AJ, Perry CA, McEntee MF, Lin DM, Stover PJ: Shmt1 heterozygosity impairs folate-dependent thymidylate synthesis capacity and modifies risk of $\mathrm{Apc}(\mathrm{min})$-mediated intestinal cancer risk. Cancer Res 2011, 71:2098-2107

60. Anderson OS, Sant KE, Dolinoy DC: Nutrition and epigenetics: an interplay of dietary methyl donors, one-carbon metabolism and DNA methylation. J Nutr Biochem 2012, 23:853-859

61. Bertolo RF, McBreairty LE: The nutritional burden of methylation reactions. Curr Opin Clin Nutr Metab Care 2013, 16:102-108

62. Crider KS, Yang TP, Berry RJ, Bailey LB: Folate and DNA methylation: a review of molecular mechanisms and the evidence for folate's role. Adv Nutr 2012, 3:21-38

63. Waterland RA: Assessing the effects of high methionine intake on DNA methylation. J Nutr 2006, 136:1706S-1710S

64. Amaral CL, Bueno Rde B, Burim RV, Queiroz RH, Bianchi Mde L, Antunes LM: The effects of dietary supplementation of methionine on genomic stability and p53 gene promoter methylation in rats. Mutat Res 2011, 722:78-83
65. Dong E, Agis-Balboa RC, Simonini MV, Grayson DR, Costa E, Guidotti A: Reelin and glutamic acid decarboxylase67 promoter remodeling in an epigenetic methionine-induced mouse model of schizophrenia. Proc Natl Acad Sci U S A 2005, 102: $12578-12583$

66. Edgar R, Tan PP, Portales-Casamar E, Pavlidis P: Meta-analysis of human methylomes reveals stably methylated sequences surrounding $\mathrm{CpG}$ islands associated with high gene expression. Epigenetics Chromatin 2014, 7:28. eCollection 2014

67. Morris MJ, Adachi M, Na ES, Monteggia LM: Selective role for DNMT3a in learning and memory. Neurobiol Learn Mem 2014, 115 : $30-37$

68. Wu H, Coskun V, Tao J, Xie W, Ge W, Yoshikawa K, Li E, Zhang Y, Sun YE: Dnmt3a-dependent nonpromoter DNA methylation facilitates transcription of neurogenic genes. Science 2010, 329: $444-448$

69. Nguyen S, Meletis K, Fu D, Jhaveri S, Jaenisch R: Ablation of de novo DNA methyltransferase Dnmt3a in the nervous system leads to neuromuscular defects and shortened lifespan. Dev Dyn 2007, 236: $1663-1676$

70. Watanabe D, Uchiyama K, Hanaoka K: Transition of mouse de novo methyltransferases expression from Dnmt3b to Dnmt3a during neural progenitor cell development. Neuroscience 2006, 142:727-737

71. Feng J, Chang H, Li E, Fan G: Dynamic expression of de novo DNA methyltransferases Dnmt3a and Dnmt3b in the central nervous system. J Neurosci Res 2005, 79:734-746

72. Mellen M, Ayata P, Dewell S, Kriaucionis S, Heintz N: MeCP2 binds to $5 \mathrm{hmC}$ enriched within active genes and accessible chromatin in the nervous system. Cell 2012, 151:1417-1430

73. Chen RZ, Akbarian S, Tudor M, Jaenisch R: Deficiency of methyl$\mathrm{CpG}$ binding protein-2 in CNS neurons results in a Rett-like phenotype in mice. Nat Genet 2001, 27:327-331

74. Amir RE, Van den Veyver IB, Wan M, Tran CQ, Francke U, Zoghbi HY: Rett syndrome is caused by mutations in X-linked MECP2, encoding methyl-CpG-binding protein 2. Nat Genet 1999, 23:185-188

75. Gemelli T, Berton O, Nelson ED, Perrotti LI, Jaenisch R, Monteggia LM: Postnatal loss of methyl-CpG binding protein 2 in the forebrain is sufficient to mediate behavioral aspects of Rett syndrome in mice. Biol Psychiatry 2006, 59:468-476

76. Kishi N, Macklis JD: MeCP2 functions largely cell-autonomously, but also non-cell-autonomously, in neuronal maturation and dendritic arborization of cortical pyramidal neurons. Exp Neurol 2010, 222:51-58

77. Deininger PL, Moran JV, Batzer MA, Kazazian HH Jr: Mobile elements and mammalian genome evolution. Curr Opin Genet Dev 2003, 13:651-658

78. Pogribny IP, Beland FA: DNA hypomethylation in the origin and pathogenesis of human diseases. Cell Mol Life Sci 2009, 66:2249-2261

79. Eden A, Gaudet F, Waghmare A, Jaenisch R: Chromosomal instability and tumors promoted by DNA hypomethylation. Science 2003, 300:455

80. Kulis M, Esteller M: DNA methylation and cancer. Adv Genet 2010, $70: 27-56$

81. Ehrlich M: DNA methylation and cancer-associated genetic instability. Adv Exp Med Biol 2005, 570:363-392

82. Wolff EM, Byun HM, Han HF, Sharma S, Nichols PW, Siegmund KD, Yang AS, Jones PA, Liang G: Hypomethylation of a LINE-1 promoter activates an alternate transcript of the MET oncogene in bladders with cancer. PLoS Genet 2010, 6:e1000917

83. Erwin JA, Marchetto MC, Gage FH: Mobile DNA elements in the generation of diversity and complexity in the brain. Nat Rev Neurosci 2014, 15:497-506

84. Portela A, Esteller M: Epigenetic modifications and human disease. Nat Biotechnol 2010, 28:1057-1068

85. Jones PA, Baylin SB: The epigenomics of cancer. Cell 2007, 128: 683-692 